\title{
Apreciación del dólar en las exportaciones de banano ecuatoriano, hacia el mercado Ruso
}

\section{Dollar appreciation in Ecuadorian banana exports, towards the Russian market}

\author{
MSc, Juan Carlos Muñoz Briones ${ }^{1}$ \\ cjmunoz@umet.edu.ec \\ MSc, Lenin Alexander Novillo Díaz ${ }^{2}$ \\ Inovillo@umet.edu.ec \\ MSc, Gunther Hans Ehmig Chum ${ }^{3}$ \\ guntherhans@hotmail.com
}

Recibido: 1/12/2018; Aceptado: 1/02/2019

\begin{abstract}
RESUMEN
La presente investigación tiene como objetivo dar a conocer las afectaciones que se pueden dar en la exportación de banano ecuatoriano al mercado ruso, dada la condición de que el dólar se encuentra apreciado frente al rublo ruso. Se realizó un estudio descriptivo de la incidencia de la apreciación del dólar en las exportaciones de banano ecuatoriano hacia ese mercado, en 2016, con la finalidad de identificar y detallar la situación actual de las exportaciones hacia el mercado meta y a su vez determinar las consecuencias de la apreciación del dólar en relación a la exportación de banano ecuatoriano hacía ese destino, desde una perspectiva del país exportador. Como resultado, la cantidad de banano exportada tiende a incrementar, pero el precio se ve reducido por parte de los compradores, al igual que la disminución de las importaciones por parte de la Federación de Rusia. Esto debido a la recesión en la cual se encuentra este país, que según previsiones empezará a mejorar su economía a mediados del 2017, siempre y cuando no se den shocks externos.
\end{abstract}

Palabras Clave: apreciación, dólar, exportación, mercado

\footnotetext{
1 Universidad Metropolitana. Ecuador

2 Universidad Metropolitana. Ecuador

3 Universidad Metropolitana. Ecuador
}

Revista científica Ciencia y Tecnología Vol 19 No 22 págs. 65-93

http://cienciaytecnologia.uteg.edu.ec 


\begin{abstract}
The objective of this article is to present the affectations that can occur in the exports of Ecuadorian bananas to the Russian market, given the condition that the dollar is appreciated against the Russian ruble. A descriptive study of the incidence of the appreciation of the dollar in exports of Ecuadorian bananas to the Russian market in 2016 was conducted, in order to identify and detail the current situation of exports to the target market and in turn, to determine the consequences of the appreciation of the dollar in relation to the exports of Ecuadorian bananas to the Russian market, from a perspective of the exporting country. As a result, the quantity of bananas exported tends to increase, but the price is reduced by the buyers, as well as the decrease in imports from the Russian Federation, due to the recession affecting that country, which according to forecasts, will begin to improve its economy in mid-2017, as long as there are no external shocks.
\end{abstract}

Keywords: appreciation, dollar, export, market

\title{
Introducción
}

El dólar americano a nivel mundial tiene una gran importancia, ya que es el protagonista del mercado de divisas en donde es el más utilizado para el tipo de cambio real y las transacciones comerciales a nivel internacional. La Reserva Federal, en el año 2014 analizó con mucha preocupación la apreciación del dólar respecto al euro, según consta en las actas de la última reunión del Banco Central Estadounidense, debido a la persistente falta de crecimiento e inflación en la zona euro. (Revista Líderes, 2015). El mismo comportamiento ha mostrado en el año 2016 y 2017, con respecto a la Unión Europea y los países de América Latina y que han sido de dominio público.

El rublo es la moneda oficial de Rusia, en los últimos meses se ha recuperado frente al euro y dólar a causa de la desvinculación del indicador de los precios de petróleo (Filomenko, 2015).

El Ecuador tiene como moneda actual el dólar norteamericano y adoptó esta moneda después de la crisis de la devaluación del sucre en el periodo 1999-2000. La economía ecuatoriana se pudo estabilizar pero se perdió soberanía monetaria. Al no contar con moneda propia, es imposible enfrentar una crisis adoptando o utilizando un mecanismo o política, y el país se vuelve dependiente de las políticas que implemente o el estado en que se encuentre los Estados Unidos de Norteamérica. Actualmente, la economía de ese país ha tenido un fuerte crecimiento, lo que ha fortalecido la moneda estadounidense frente a otras divisas.

En el Ecuador, la actividad bananera genera fuentes de trabajo e ingresos a dos millones de personas involucradas en las diferentes etapas de su cadena de valor (Pro Ecuador, 2016).

En el 2015 el sector bananero ecuatoriano exportó al mercado ruso, dando un resultado de unidades monetarias de 529 mil dólares valor FOB (Fuenmayor, 2015) a diferencia en el año 2016 en el que hubo un total de 535 mil dólares valor FOB. Por ende el banano ecuatoriano es el primer producto de exportación hacia el mercado ruso. Así mismo, se lo considera como un mercado potencial para el sector bananero 


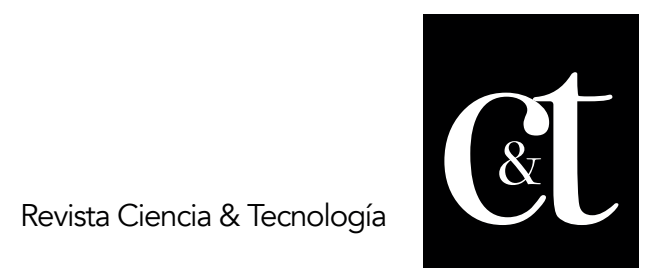

No. 22, 30 de abril de 2019

ISSN impreso: 1390 - 6321

ISSN online: 2661 - 6734

del Ecuador. Esta situación puede ser alterada debido a las fluctuaciones del dólar que han hecho que el sector bananero ecuatoriano sea más competitivo o pueden volverlo menos competitivo (Centro de Comercio Internacional, 2017).

El objetivo principal de este trabajo es el de identificar la incidencia de la apreciación del dólar estadounidense en las exportaciones del banano ecuatoriano hacia el mercado ruso. Además, se pretende diagnosticar la situación de las exportaciones del banano ecuatoriano al mercado de ese país, anterior a dicha apreciación. También se quiere establecer de qué manera esa apreciación de la divisa estadounidense ha incidido en el comercio bilateral ecuatoriano-ruso.

\section{Desarrollo}

Dentro de la temática planteada para el presente trabajo investigativo no he identificado un trabajo académico relacionado con la incidencia de la apreciación del dólar en las exportaciones de banano ecuatoriano hacia el mercado ruso, 2015-2016.

Metodología para medir la apreciación del dólar

Se trabajará con los conceptos ya conocidos, como son:

Tipo de cambio nominal: Es el precio en dólares de una moneda extranjera. Es una variable que vincula el precio de dos monedas. Usualmente hace referencias a la cotización de dólar respecto al euro; es decir cuántos dólares se requieren para comprar un euro (Álvarez, 2010).

Tipo de cambio real:

Se encarga de medir el grado de competitividad de nuestros productos con respectos a los productos extranjeros. El tipo de cambio real resulta de multiplicar el tipo de cambio nominal por el nivel de precios del exterior y dividir todo entre el nivel de precios internos (Álvarez, 2010).

$$
\varepsilon=E \frac{P^{*}}{P}
$$

$\mathrm{P}^{*}=$ índice de precios de los bienes y servicios extranjeros

$\mathrm{P}=$ índice de precios de los bienes y servicios nacionales

Tipo de cambio real bilateral:

Se basa en la relación entre los índices de precios al consumidor del país en cuestión, con el índice de precios de los Estados Unidos, multiplicado por el tipo de cambio nominal del año base. Luego, este resultado se resta del tipo de cambio nominal: si la diferencia es positiva (se suma a uno) indica el nivel de apreciación; si es negativa (se resta de uno) refleja el nivel de depreciación.
1) $T C R B=\frac{P}{P^{*}} \times$ TCNbase
2) $A o D=T C R B-T C N$ 
TCRB = tipo de cambio real bilateral

$\boldsymbol{P}=$ índice de precios del país i

$\boldsymbol{P}^{*}=$ índice de precios de Estados Unidos

$\mathrm{TCN}=$ tipo de cambio nominal

AoD = apreciación o depreciación de la moneda interna

Mercado de divisas

Mercado de divisas es el espacio, la situación o el contexto donde se lleva a cabo el intercambio, la venta y la compra de monedas extranjeras llamadas divisas. Al ser un mercado, el precio de las divisas está determinado por la oferta y la demanda que existan sobre ellas.

Los intercambios de divisas generalmente se hacen en grandes centros financieros del mundo Londres, Nueva York y Singapur son unos de los más importantes. Los principales participantes en el mercado de divisas son los bancos, las multinacionales, las instituciones financieras no bancarias y los bancos centrales.

Para el caso de los bancos, éstos efectúan transacciones entre cuentas de clientes a nivel internacional. Generalmente, los bancos especifican el tipo de divisas utilizadas en sus operaciones y transacciones.

Además de realizar transacciones para clientes, los bancos realizan operaciones con divisas como negocio, pues los clientes de los bancos pagan por ellas un precio de menudeo que es mayor al precio al cual los bancos las compran (pues los bancos las compran "al por mayor"). La diferencia en los precios es la compensación que reciben los bancos por desarrollar esta actividad.

Las empresas multinacionales, al hacer presencia en varios países, negocian con monedas diferentes. Las instituciones financieras no bancarias, como los fondos de pensiones, al manejar grandes sumas de dinero, también negocian con monedas diferentes.

Los bancos centrales también participan activamente en el mercado de divisas. Las reservas internacionales de los países están invertidas, en su mayoría, en divisas. Dependiendo de las economías, el dinero en circulación en éstas y las políticas económicas, los bancos centrales deciden entrar o no en el mercado de divisas para comprar o vender (Dabrowsky, 2015).

El mercado de divisas se caracteriza por su constante variación y por la constante demanda de información por parte de los participantes.

El dólar es una moneda fundamental en este mercado. Muchas transacciones entre monedas se hacen con la intervención del dólar. Por ejemplo: si uno quiere vender euros y comprar rublos, la transacción se haría cambiando los euros por dólares y después los dólares por rublos. Por eso al dólar se lo considera como una "moneda 


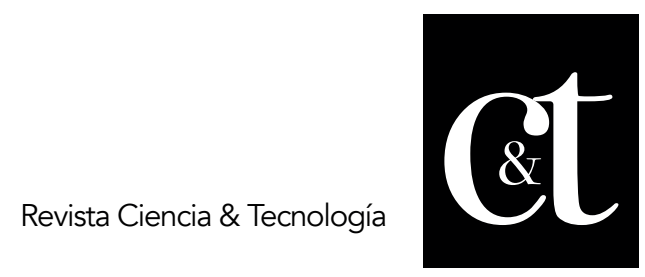

No. 22, 30 de abril de 2019

ISSN impreso: 1390 - 6321

ISSN online: 2661 - 6734

conductora".

Las divisas también se negocian en el llamado mercado negro. Un mercado negro aparece cuando las autoridades ponen barreras al libre mercado. El mercado negro no se considera legal, por lo tanto, no se encuentra controlado o regulado, y negociar en éste es ir contra la ley (Krugman y Obstfeld, 2011).

La dolarización

La definición de dolarización, es el proceso en el cual el dinero extranjero reemplaza físicamente al nacional. Este fenómeno es un caso particular de sustitución de la moneda local por el dólar estadounidense, así el dólar reemplaza en sus funciones a la moneda local (Herrera \& Caballero, 2012).

Con relación a la fortaleza del dólar, al Ecuador le afecta en forma ambivalente: ahora y en el mediano plazo esta moneda será más fuerte que las demás y su poder de compra aumentará el valor intrínseco de sus transacciones comerciales, financieras y crediticias. Para empezar, si el dólar sigue fuerte, el precio del petróleo disminuirá concomitantemente y entonces el Ecuador recibirá menos dólares aunque manteniendo su mayor poder adquisitivo frente al de otras monedas del mundo (Herrera, 2015).

\section{Apreciación y Depreciación}

Factores que pueden afectar la apreciación o depreciación de la moneda

Según (Carty, 2017), determina lo siguientes factores:

- Oferta y demanda

Al igual que con los bienes y servicios, los principios de la oferta y demanda aplican a la apreciación y depreciación de los valores de la moneda. Si un país inyecta una nueva moneda a su economía, incrementa el suministro de dinero. Cuanto más dinero hay circulando en una economía, hay menos demanda. Esto deprecia el valor de la moneda. Cuando hay una demanda alta extranjera o interna por la moneda de un país, sube su valor.

- Inflación y deflación

La inflación sucede cuando los precios generales de los bienes y servicios en un país se incrementan. La inflación provoca que el valor del dólar se deprecie, reduciendo el poder de compra. La deflación ocurre cuando los precios generales de los bienes y servicios disminuyen. La deflación incrementa el poder de compra del dinero y provoca que su valor se aprecie. Generalmente ocurre en ocasiones cuando la economía está experimentando un crecimiento económico lento o ningún crecimiento. Durante los tiempos de deflación, los negocios regularmente disminuyen los precios de sus bienes y servicios para encontrar compradores.

- Perspectivas económicas

Si la economía de un país tiene un crecimiento lento o está en una fase de recesión, el valor de su moneda se aprecia (Forbes, 2014). El valor de la moneda de un país también se deprecia si los indicadores de economías principales como las ventas de 


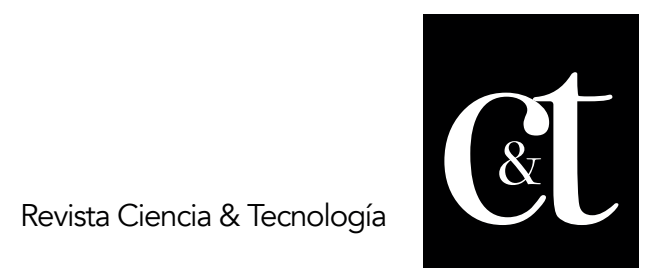

No. 22, 30 de abril de 2019

ISSN impreso: 1390 - 6321

ISSN online: 2661 - 6734

menudeo y el Producto Interno Bruto, o PIB, están declinando. Una tasa creciente y/o elevada de desempleo también puede despreciar el valor de la moneda debido a que indica un retraso económico (CEE, 2015). Si la economía está en un periodo de crecimiento fuerte, el valor de su moneda se aprecia. La apreciación también sucede cuando los indicadores de economías principales como el Producto Interno Bruto y las ventas de menudeo están elevándose (Castillo, 2007).

- Déficit de comercio

Un déficit de comercio sucede cuando el valor de los bienes que un país importa es mayor que el valor de los bienes que exporta. Cuando el déficit de comercio de un país se incrementa, el valor de la moneda doméstica se deprecia contra el valor de la moneda de sus compañeros de comercio. Cuando el déficit de comercio de un país disminuye, pero el país permanece en déficit, el valor de su moneda doméstica aprecia en contra del valor de la moneda de sus compañeros de comercio (EcoFinanzas, 2015).

\section{¿Qué provoca una depreciación?}

El tipo de cambio es el precio de una moneda respecto de otra y como todo precio es el resultado de la interacción entre oferta y demanda, en este caso, de la oferta y demanda de divisas (o en sentido inverso de la demanda de moneda nacional). Se producirá una depreciación de la moneda nacional cuando se produzca un exceso de oferta de la moneda nacional (López Domínguez, s.f.).

Efectos de la depreciación de la moneda nacional

- Se da un aumento en la actividad económica, en la medida en que se registrará un aumento en la demanda agregada, como consecuencia del incremento en las exportaciones y el descenso en las importaciones.

- Se genera una mejora en la balanza comercial y en la balanza de bienes y servicios, siempre que el efecto volumen de reducción en las importaciones sea superior al efecto precio de encarecimiento (esta condición es habitualmente conocida como condición de Marshall-Lerner).

- Un aumento en la tasa de inflación, debido al encarecimiento de los bienes y servicios importados cuando se expresan en moneda nacional (Vaswani, 2015).

- Se ocasiona una mejora en la competitividad de los productos de fabricación nacional respecto a los productos fabricados en el exterior.

- Hay un deterioro en la relación real de intercambio (López Domínguez, s.f.).

Estructura arancelaria para el subsector (Código arancelario en Ecuador (NANDINA) y descripción del producto) 
Tabla 1. Estructura arancelaria para el subsector

\begin{tabular}{|l|l|}
\hline CÓDIGO ARANCELARIO & \multicolumn{1}{|c|}{ DESCRIPCIÓN } \\
\hline 803 & $\begin{array}{l}\text { Bananas, incluidos los plátanos } \\
\text { «plantains», frescos o secos. }\end{array}$ \\
\hline 0803.90 & - Los demás: \\
\hline & - - - Frescos: \\
\hline 0803.90 .11 & -- - Tipo «cavendish valery» \\
\hline
\end{tabular}

Fuente: Arancel Nacional de Importaciones de Ecuador, V Enmienda 2012.

\section{Métodos}

Estudio descriptivo

Se realizará un estudio descriptivo de la incidencia de la apreciación del dólar en las exportaciones de banano ecuatoriano hacia el mercado ruso, 2016. Se aplicará con la finalidad de identificar y detallar la situación actual de las exportaciones hacia el mercado meta, y a su vez determinar las consecuencias de la apreciación del dólar en relación a la exportación de banano ecuatoriano hacía el mercado ruso, desde una perspectiva del país exportador.

Modalidad de investigación

Para la presente investigación se aplicará la modalidad de investigación documental a que agrupa los requisitos técnicos necesarios para la realización del presente trabajo.

Metodología específica

Metodología de comercio exterior

Para la realización de esta investigación en forma secuencial y técnica se hizo mención al desarrollo operativo de los objetivos específicos planteados.

- Recopilación de información primaria y secundaria proporcionada por PROECUADOR, AEBE, y Banco Central del Ecuador sobre las exportaciones del sector bananero hacia el mercado ruso.

- Acceso a repositorios digitales para obtener información de fuentes secundarias, tales como artículos científicos, libros, revistas.

- Examinar las cifras proyectadas en la herramienta TradeMap.

- Comprobar y calcular la variación de la tasa de cambio del dólar frente al rublo en los últimos 3 años.

- Analizar la situación actual de las exportaciones de banano ecuatoriano hacia el mercado ruso.

- Comprobar si existe incidencia en la apreciación del dólar en las exportaciones del sector bananero ecuatoriano. 


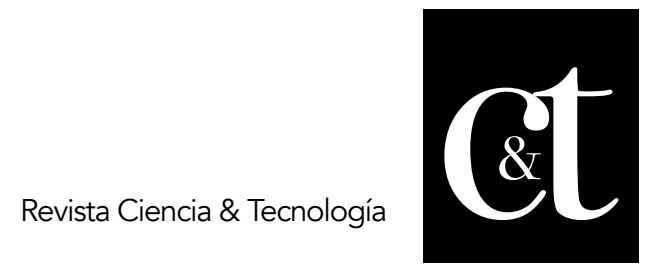

No. 22, 30 de abril de 2019

ISSN impreso: 1390 - 6321

ISSN online: 2661 - 6734

- Determinar las posibles ventajas de la apreciación del dólar frente al rublo.

\section{Resultados}

Análisis de la situación de las exportaciones de banano ecuatoriano al mercado ruso anteriores a la apreciación del dólar (Férrero, 2016).

Ecuador es el mayor exportador del banano en el mundo, siendo además el principal exportador de banano a la Federación Rusa. Desde el año 2008 el Ecuador ha mantenido una balanza comercial positiva con este país a través de la exportación de productos de más de 74 partidas, cantidades de las cuales el banano representa el $80 \%$ del total exportado a dicho país. (Comercio exterior, 2016).

Tabla 2. Indicadores comerciales

\begin{tabular}{|c|c|c|c|c|c|c|}
\hline \multirow[b]{2}{*}{$\begin{array}{c}\text { Exportado } \\
\text { res }\end{array}$} & \multicolumn{6}{|c|}{ Indicadores comerciales } \\
\hline & $\begin{array}{c}\text { Valor } \\
\text { importado } \\
\text { en } 2016 \\
\text { (miles de } \\
\text { USD) }\end{array}$ & $\begin{array}{c}\text { Particip. } \\
\text { en \% de } \\
\text { importaci } \\
\text { ones } \\
\text { Rusia }\end{array}$ & $\begin{array}{c}\text { Cantidad } \\
\text { importada } \\
\text { en } 2016\end{array}$ & $\begin{array}{c}\text { Unidad } \\
\text { de } \\
\text { medida }\end{array}$ & $\begin{array}{c}\text { Val } \\
\text { or } \\
\text { uni } \\
\text { tari } \\
\text { o } \\
\text { (USD/u } \\
\text { nidad) }\end{array}$ & $\begin{array}{c}\text { Tasa de } \\
\text { crecimien } \\
\text { to de los } \\
\text { valores } \\
\text { importada } \\
\text { s entre } \\
2015- \\
2016 \\
\text { (\%) } \\
\text { p.a.) }\end{array}$ \\
\hline Mundo & 909850 & 100 & 1226511 & $\begin{array}{l}\text { Tonelada } \\
\text { s }\end{array}$ & 742 & -5 \\
\hline Ecuador & 896225 & 98,5 & 1209044 & Toneladas & 741 & -3 \\
\hline $\begin{array}{l}\text { Costa } \\
\text { Rica }\end{array}$ & 7243 & 0,8 & 9591 & Toneladas & 755 & -32 \\
\hline Filipinas & 2825 & 0,3 & 3597 & Toneladas & 785 & -79 \\
\hline México & 2118 & 0,2 & 3030 & Toneladas & 699 & 85 \\
\hline Viet Nam & 942 & 0,1 & 675 & Toneladas & 1396 & -33 \\
\hline Brasil & 361 & 0 & 416 & Toneladas & 868 & -75 \\
\hline Colombia & 35 & 0 & 38 & Toneladas & 921 & -94 \\
\hline Honduras & 34 & 0 & 47 & Toneladas & 723 & \\
\hline China & 23 & 0 & 22 & Toneladas & 1045 & -74 \\
\hline India & 23 & 0 & 44 & Toneladas & 523 & \\
\hline Tailandia & 19 & 0 & 5 & Toneladas & 3800 & -78 \\
\hline
\end{tabular}

Fuente: Trade Map

En el mercado ruso las importaciones de banano ecuatoriano representaron en el 2015 el 98,5\% del total importado por la partida 0803 correspondiente a la fruta. Esta relación de negocios se ha venido dando desde antes del ingreso de la Federación de Rusia a la Organización Mundial del Comercio (OMC), por lo que el gobierno ecuatoriano ha incentivado la producción de la fruta dentro del territorio nacional, promoviendo y desarrollando la exportación de productos no petroleros siendo este el producto no petrolero estrella del país (Macas, 2014). 
La exportación de banano a Rusia se ha ido desarrollando a través del tiempo, teniendo en consideración que a principios de los 90 's el Ecuador exportaba a este país alrededor de 10.000 toneladas métricas hasta convertirse actualmente en el mayor proveedor de la fruta en el país.

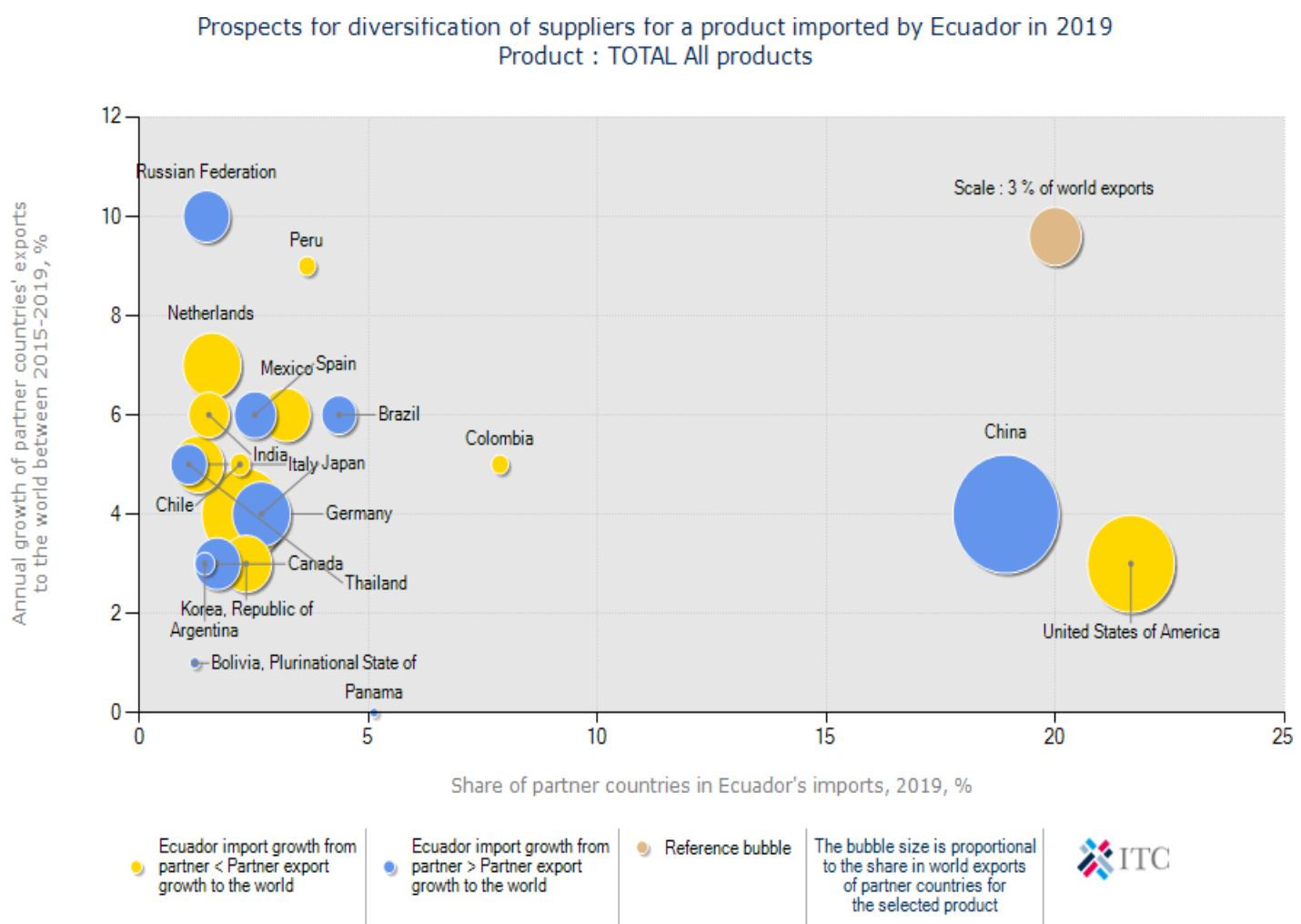

Gráfico 1. Países proveedores de banano a Federación Rusa Fuente: Trademap

La mayoría de los proveedores de banano al mercado ruso tienen una característica en común, su clima, siendo el clima cálido - húmedo el más propicio para el cultivo de los plátanos, ante esta regla hay una excepción: Bélgica, no cuenta con un clima similar al de sus competidores exportadores, pero su crecimiento de re exportación se destaca debido a que es un punto de llegada para las mercancías a Europa, siendo esto propicio para el acrecentamiento de la economía por este rubro. 


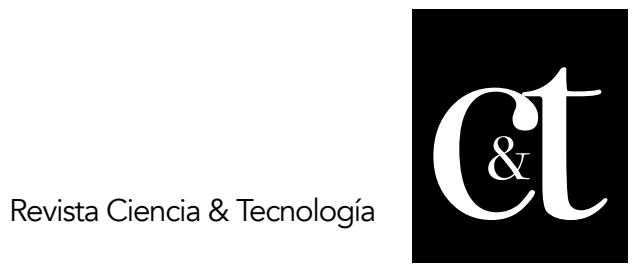

No. 22, 30 de abril de 2019

ISSN impreso: 1390 - 6321

ISSN online: 2661 - 6734

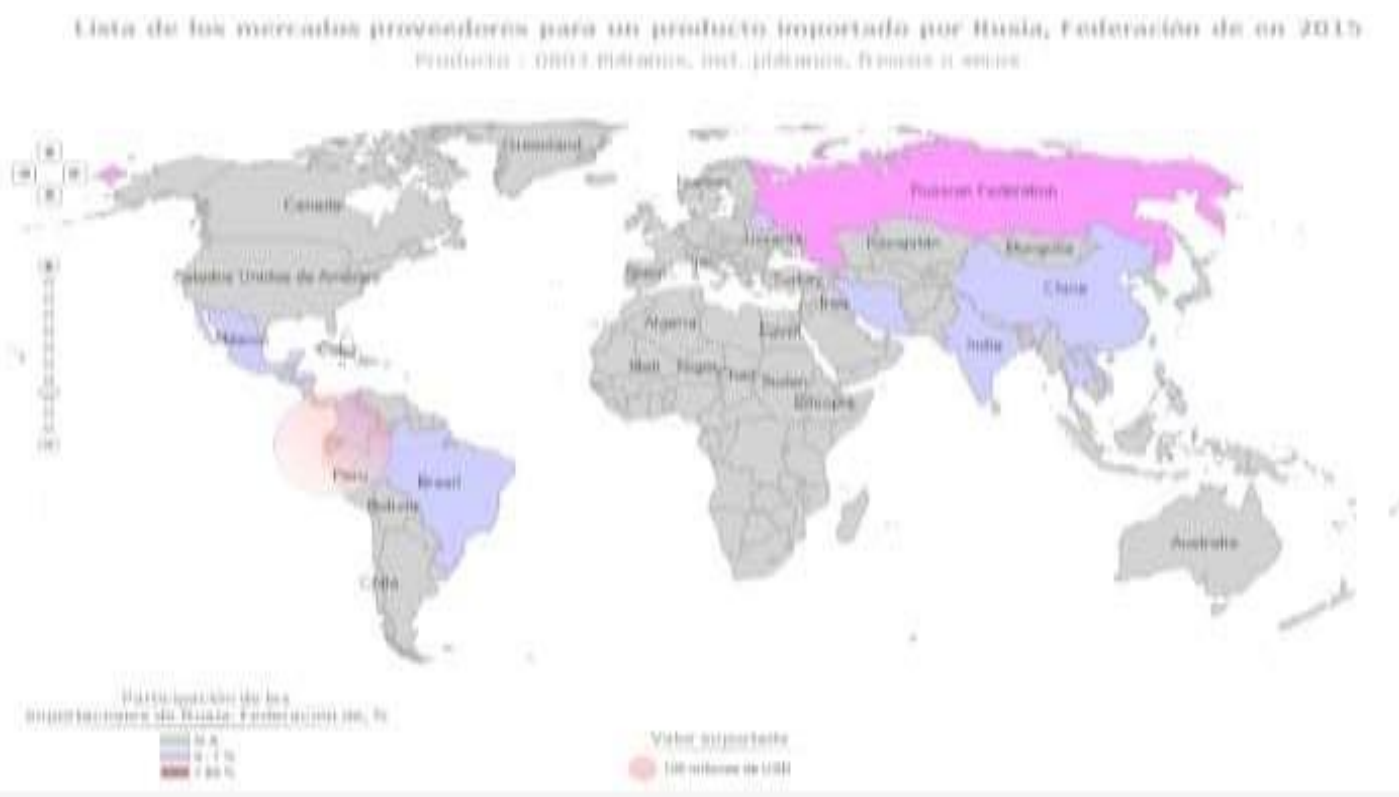

\section{Gráfico 2. Lista de mercados proveedores de Rusia}

Fuente: TradeMap

La distancia entre Ecuador y la Federación Rusa no ha impedido que cada año aumente la exportación del banano hacia el destino euro asiático, dejando de lado a productores más cercanos como Las Filipinas o China debido al insuperable sabor y textura del banano ecuatoriano que cobijado bajo el clima propicio para el cultivo necesita menos de la mitad de fungicidas que los cultivados en países competidores.

Exportación de banano del Ecuador al mercado ruso

Las exportaciones de banano al mercado ruso dan como resultado un valor de $\$ 37^{\prime} 163,567.23$ convenientemente exportado al mencionado mercado. En el Ecuador existen alrededor de 200 empresas exportadoras, sin embargo, solamente cuatro de ellas abarcan la mayor parte del mercado, favoreciendo a la concentración de poder y normas para la exportación, es por ello destacable resaltar que los pequeños productores se están asociando para poder aumentar la cuota de exportación y mejorar sus procesos productivos.

El mercado ruso demanda actualmente 1'300.000 cajas de banano Cavendish, 16.000 cajas de baby banana y 2.000 cajas de red bananas.

Principales países exportadores de Banano a Rusia

Al ser Rusia un gran mercado con \# de habitantes se convierte en el premio mayor de Eurasia. Ecuador desde sus incipientes comienzos de relaciones bilaterales con la Federación Rusa se ha destacado por su importante cuota de mercado en referencia al banano, siendo actualmente el mayor proveedor de la fruta en el país destacándose por la calidad del producto lo que se denota en los valores importados a lo largo de este tiempo. 
Tabla 3. Valores exportados a Rusia

\begin{tabular}{|c|c|c|c|c|c|c|}
\hline \multicolumn{7}{|c|}{ Valores expresados en miles (USD) } \\
\hline Exportadores & $\begin{array}{l}\text { Valor } \\
\text { importado } \\
\text { en } 2012\end{array}$ & $\begin{array}{l}\text { Valor } \\
\text { importado } \\
\text { en } 2013\end{array}$ & $\begin{array}{l}\text { Valor } \\
\text { importado } \\
\text { en } 2014\end{array}$ & $\begin{array}{l}\text { Valor } \\
\text { importado } \\
\text { en } 2015\end{array}$ & $\begin{array}{l}\text { Valor } \\
\text { importado } \\
\text { en } 2016\end{array}$ & $\begin{array}{l}\text { Valor } \\
\text { Total } \\
\text { import } \\
\text { ado } \\
2012- \\
2017\end{array}$ \\
\hline Ecuador & 546845 & 596353 & 584343 & 642092 & 872867 & $\begin{array}{r}32425 \\
00\end{array}$ \\
\hline Costa Rica & 1401 & 48778 & 21443 & 32908 & 27561 & $\begin{array}{r}13209 \\
1\end{array}$ \\
\hline Filipinas & 15834 & 20967 & 16119 & 19456 & 24881 & 97257 \\
\hline Colombia & 14287 & 155 & 3441 & 6329 & 13470 & 37682 \\
\hline China & 4214 & 3467 & 2564 & 1720 & 947 & 12912 \\
\hline Panamá & 238 & 238 & 378 & 50 & 8735 & 9639 \\
\hline México & - & - & 1721 & 783 & 356 & 2860 \\
\hline Vietnam & 188 & 366 & 347 & 533 & 1358 & 2792 \\
\hline Brasil & - & - & - & 110 & 78 & 188 \\
\hline Argentina & - & 26 & - & - & 61 & 87 \\
\hline
\end{tabular}

Fuente: TradeMap

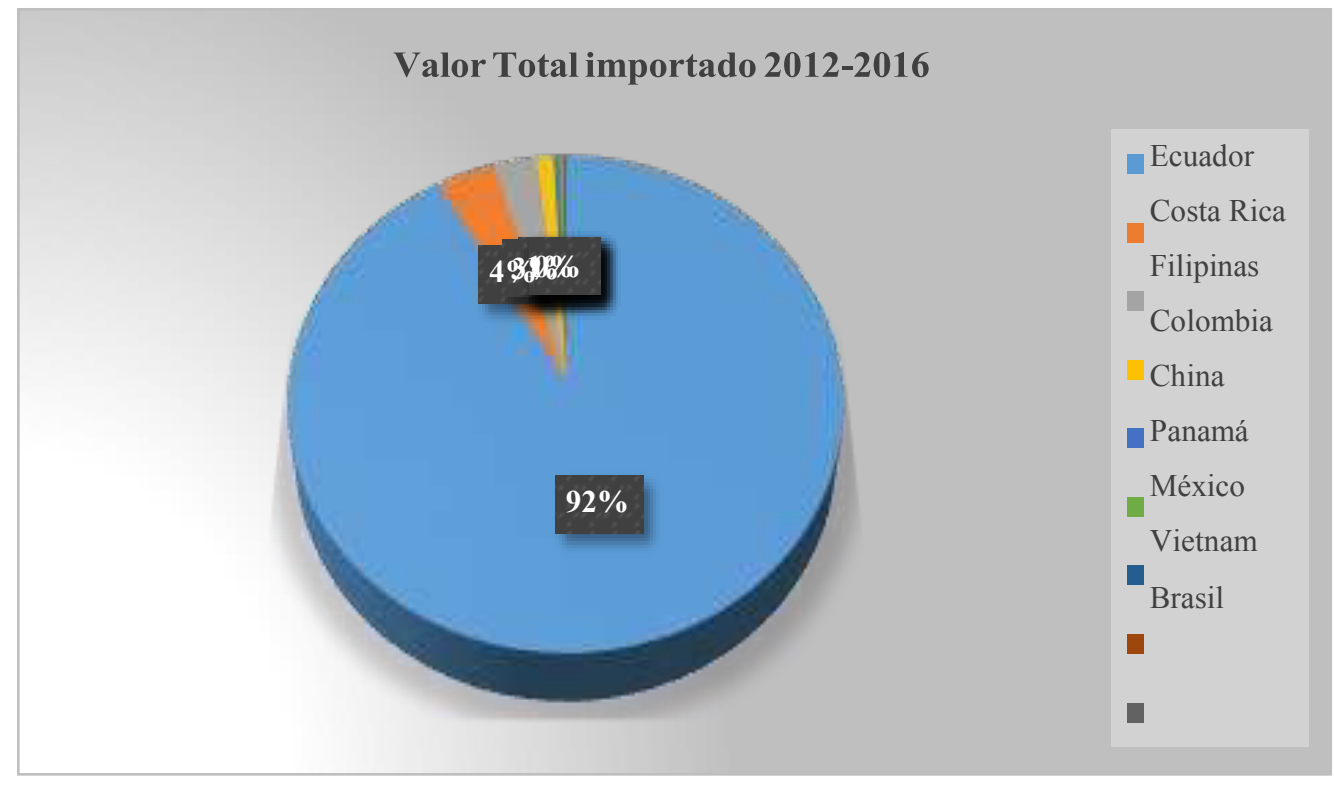

\section{Gráfico 3. Importaciones del 2012 - 2016}

Fuente: TradeMap

En el pastel del mercado ruso el Ecuador es el notable destacado debido al producto no petrolero estandarte en las exportaciones, el banano. Valores los cuales lo colocan como el notable monopolista de exportaciones en ese mercado en específico. Los 


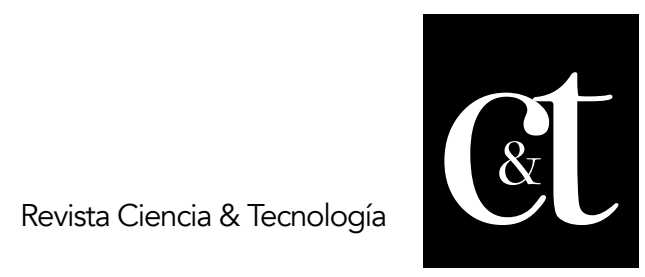

No. 22, 30 de abril de 2019

ISSN impreso: 1390 - 6321

ISSN online: 2661 - 6734

países que se destacan levemente son Costa Rica y las Filipinas.

Barreras arancelarias y acuerdos comerciales Rusia

Las barreras de entrada al mercado ruso son medidas tomadas para aprovechar el incipiente y continuo crecimiento que tiene la fruta dentro de la economía del país, es por ello que el importador de Rusia aplica la siguiente tarifa a las importaciones con la sub partida 0803.00, procedentes del Ecuador.

Tabla 4. Barreras arancelarias

\begin{tabular}{|l|l|l|l|c|}
\hline $\begin{array}{l}\text { Código del } \\
\text { producto }\end{array}$ & $\begin{array}{l}\text { Descripción } \\
\text { del producto }\end{array}$ & $\begin{array}{l}\text { Descripció } \\
\text { n Régimen } \\
\text { Comercial }\end{array}$ & $\begin{array}{l}\text { Tarifa } \\
\text { Aplicada } \\
\text { Tarifa del } \\
\text { total } \\
\text { AdValorem } \\
\text { (estimado) }\end{array}$ \\
\hline 0803009000 & $\begin{array}{l}\text { Plátanos, } \\
\text { incl. Plátanos, } \\
\text { frescos o } \\
\text { secos: seca }\end{array}$ & $\begin{array}{l}\text { Arancelario } \\
\text { preferencial para } \\
\text { los países del SGP }\end{array}$ & $\begin{array}{c}3,75 \% \\
018,31 / \text { ton }\end{array}$ & $3,75 \%$ \\
\hline
\end{tabular}

Fuente: Market Acces Map

Resultados de la exportación de banano en el 2016

Los resultados que se apreciaron al finalizar el año en la producción de banano no fueron los que se tenían previstos, esto debido a que durante el periodo de revisión esta variable presenta un decrecimiento del $1 \%$, diferencia que se hace evidente al crecer en un $3 \%$ en el año anterior.

Por otro lado, este decrecimiento bananero no ha influido en las buenas condiciones vegetativas y productivas de la fruta. Según las cifras de la Asociación de Exportadores de Banano del Ecuador (AEBE), el país exportó durante el 2016 un total de $315,329,995$ cajas de $18.14 \mathrm{Kg}$., esto implicó una variación positiva de 17,271,581 cajas de banano en relación al año anterior, en el cual, según datos de la entidad, se exportaron $298,058,414$ cajas, lo que significa un crecimiento de $6.5 \%$, con un promedio mensual de $26,453,087$ cajas. 


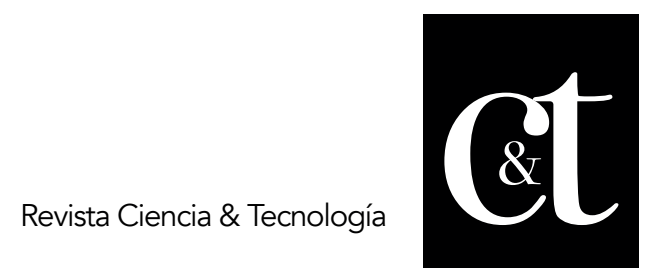

No. 22, 30 de abril de 2019

ISSN impreso: 1390 - 6321

ISSN online: 2661 - 6734

Tabla 5. Exportaciones mensuales de banano, cajas de $18,14 \mathbf{~ k g}$

\begin{tabular}{|l|c|c|c|c|}
\cline { 5 - 5 } \multicolumn{1}{|c}{ Mes } & $\mathbf{2 0 1 6}$ Cajas & $\mathbf{2 0 1 5}$ Cajas & Absoluta & $\begin{array}{c}\text { Relativa } \\
\%\end{array}$ \\
\hline Enero & 27.755 .976 & 28.483 .404 & -727.428 & $-2,55$ \\
\hline Febrero & 25.284 .665 & 22.255 .599 & 3.029 .066 & 13,61 \\
\hline Marzo & 29.455 .120 & 26.066 .618 & 3.388 .502 & 13,00 \\
\hline Abril & 26.648 .680 & 25.992 .013 & 656.667 & 2,53 \\
\hline Mayo & 29.334 .822 & 25.339 .678 & 3.995 .144 & 15,77 \\
\hline Junio & 25.441 .699 & 23.795 .559 & 1.646 .140 & 6,92 \\
\hline Julio & 26.023 .866 & 23.999 .735 & 2.024 .131 & 8,43 \\
\hline Agosto & 24.914 .793 & 22.875 .129 & 2.039 .664 & 8,92 \\
\hline $\begin{array}{l}\text { Septiembr } \\
\text { e }\end{array}$ & 24.930 .065 & 23.184 .910 & 1.745 .155 & 7,53 \\
\hline Octubre & 23.034 .019 & 24.200 .913 & -1.166 .894 & $-4,82$ \\
\hline Noviembre & 24.421 .456 & 26.297 .457 & -1.876 .001 & $-7,13$ \\
\hline Diciembre & 28.084 .834 & 25.567 .399 & 2.517 .435 & 9,85 \\
\hline TOTALES & $\mathbf{3 1 5 . 3 2 9 . 9 9 5}$ & $\mathbf{2 9 8 . 0 5 8 . 4 1 4}$ & $\mathbf{1 7 . 2 7 1 . 5 8 1}$ & $\mathbf{5 , 7 9}$ \\
\hline
\end{tabular}

Fuente: Datacomex S.A.

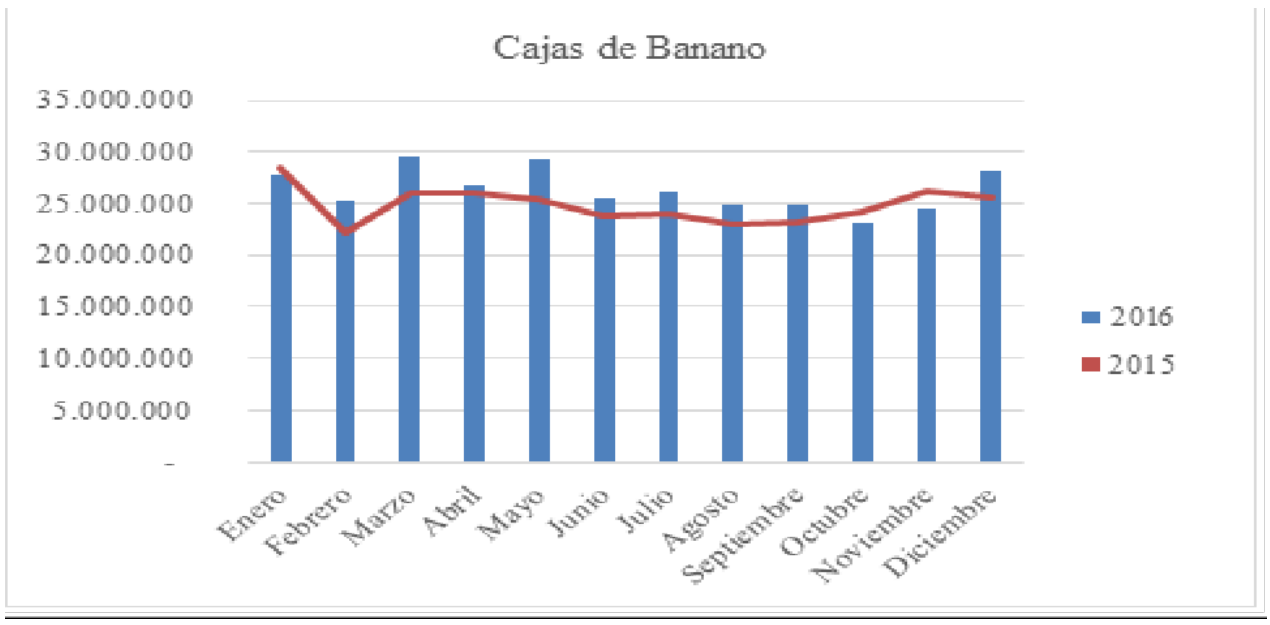

Gráfico 4. Exportación de banano

Fuente: Datacomex S.A. 


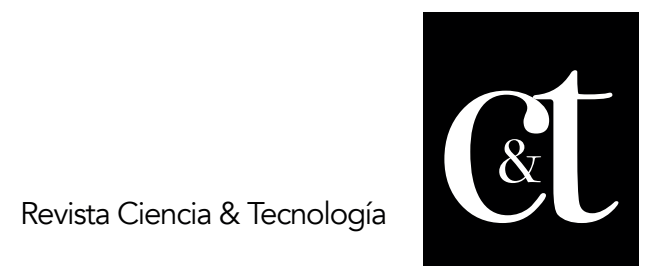

No. 22, 30 de abril de 2019

ISSN impreso: 1390 - 6321

ISSN online: 2661 - 6734

Al realizar las comparaciones de exportaciones semanales entre el 2015 y 2016 se denota un incremento del $4.49 \%$, con una variación positiva de 257,441 cajas, pasando de 5,731, 937 cajas semanales a 5, 989,378 cajas semanales, en 2015.

Tabla 6. Comparativo de las exportaciones por destino

\begin{tabular}{|l|c|c|c|c|}
\cline { 4 - 5 } \multicolumn{1}{|c}{ Destino } & $\mathbf{2 0 1 6}$ Cajas & $\mathbf{2 0 1 5}$ Cajas & Absoluta & Relativa \% \\
\hline Mar del norte & 81.308 .397 & 76.391 .274 & 4.917 .123 & 6,44 \\
\hline Rusia & 68.115 .550 & 66.553 .529 & 1.562 .021 & 2,35 \\
\hline Estados Unidos & 47.982 .908 & 44.710 .461 & 3.272 .447 & 7,32 \\
\hline Medio Oriente & 38.611 .346 & 29.458 .156 & 9.153 .190 & 31,07 \\
\hline Cono sur & 22.910 .511 & 21.860 .549 & 1.049 .962 & 4,80 \\
\hline Oriente & 17.250 .629 & 13.442 .386 & 3.808 .243 & 28,33 \\
\hline Europa del Ese & 16.498 .481 & 23.250 .549 & -6.752 .068 & $-29,04$ \\
\hline Mediterráneo & 15.181 .971 & 16.884 .534 & -1.702 .563 & $-10,08$ \\
\hline África & 6.767 .913 & 3.191 .207 & 3.576 .706 & 112,08 \\
\hline Oceanía & 2.809 .334 & 2.318 .102 & 491.232 & 21,19 \\
\hline TOTAL & 315.329 .995 & 298.058 .414 & 17.271 .581 & 6,50 \\
\hline
\end{tabular}

Fuente: TradeMap

Siendo el banano el estandarte de las exportaciones ecuatorianas no petroleras en el mundo, se destacan los mercados hacia los que se dirige, entre otros los europeos que tienen las cotas de importación de banano ecuatoriano más altas, sin contar con los Estados Unidos de Norteamérica. 


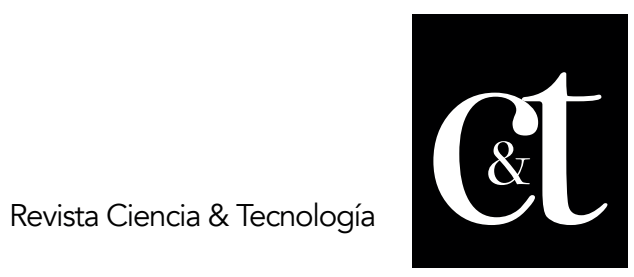

No. 22, 30 de abril de 2019

ISSN impreso: 1390 - 6321

ISSN online: 2661 - 6734

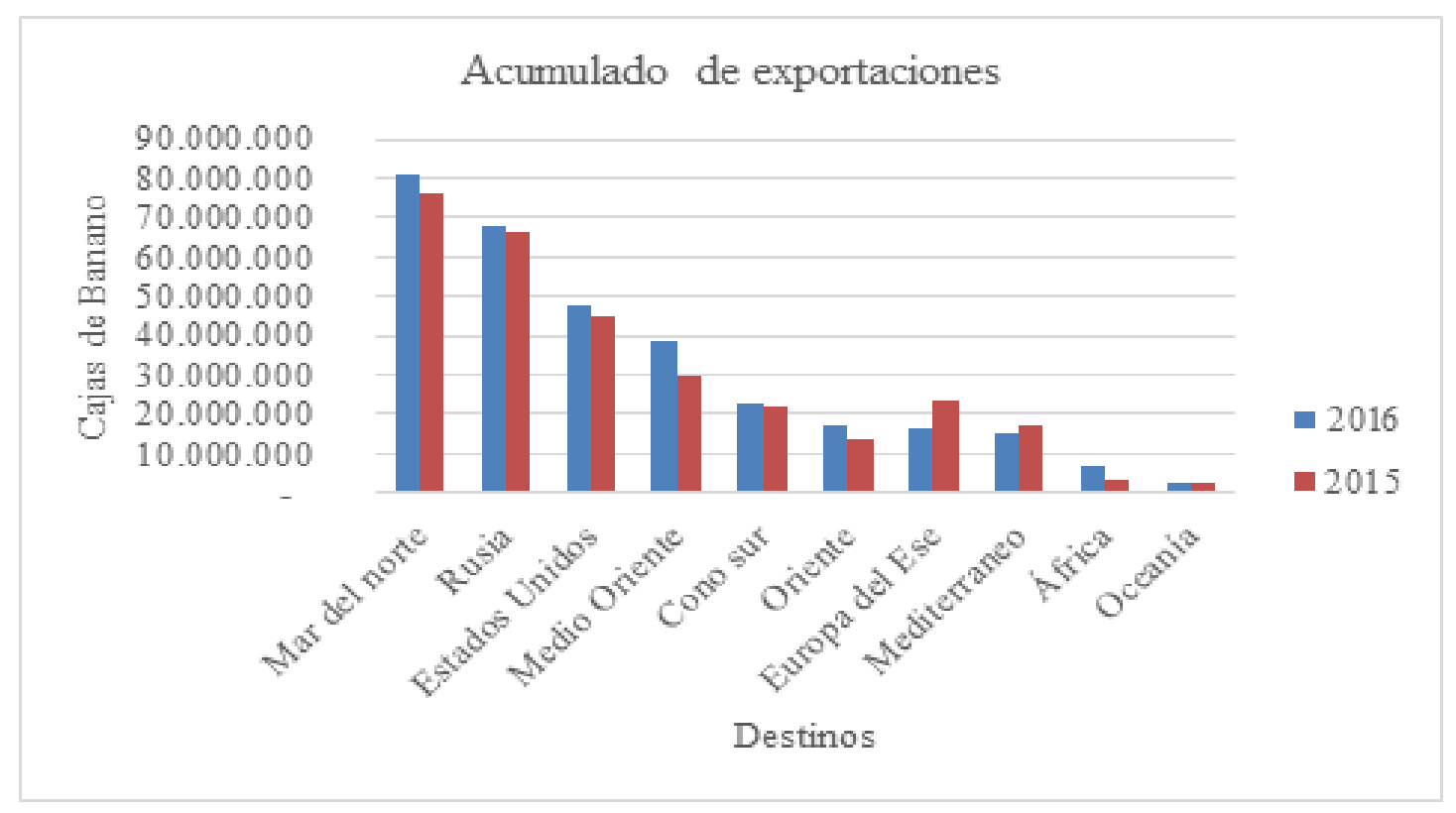

Gráfico 5: Acumulado de exportaciones 2015 - 2016

Fuente: TradeMap

Al establecer comparaciones entre el 2015 y el 2016 se evidencian variaciones ente estos años, con mayoría de tendencias de crecimiento salvo en los países de Europa del Este y de la zona del Mediterráneo, en los que decreció para el año 2016. En la zona del Mar del Norte se aprecia un significativo crecimiento de las importaciones de la fruta. En la Federación Rusa se denota un ligero crecimiento esto debido al aumento de la cantidad exportable desde el Ecuador.

Tabla 7. Volúmenes de embarque

\begin{tabular}{|l|r|c|}
\hline \multicolumn{1}{|c|}{ Destino } & Volumen & Porcentaje \\
\hline Rusia & 68.115 .550 & 21,46 \\
\hline Estados Unidos & 47.982 .908 & 15,12 \\
\hline Medio Oriente & 38.611 .346 & 12,16 \\
\hline Cono Sur & 22.910 .511 & 7,22 \\
\hline Oriente & 17.250 .629 & 5,43 \\
\hline Europa del Este & 16.498 .481 & 5,20 \\
\hline Mediterráneo & 15.181 .971 & 4,78 \\
\hline África & 6.767 .913 & 2,13 \\
\hline Oceanía & 2.809 .334 & 0,89 \\
\hline Mar del Norte & 81.308 .397 & 25,61 \\
\hline Total & $\mathbf{1 5 . 3 2 9 . 9 9 5}$ & $\mathbf{1 0 0}$ \\
\hline
\end{tabular}




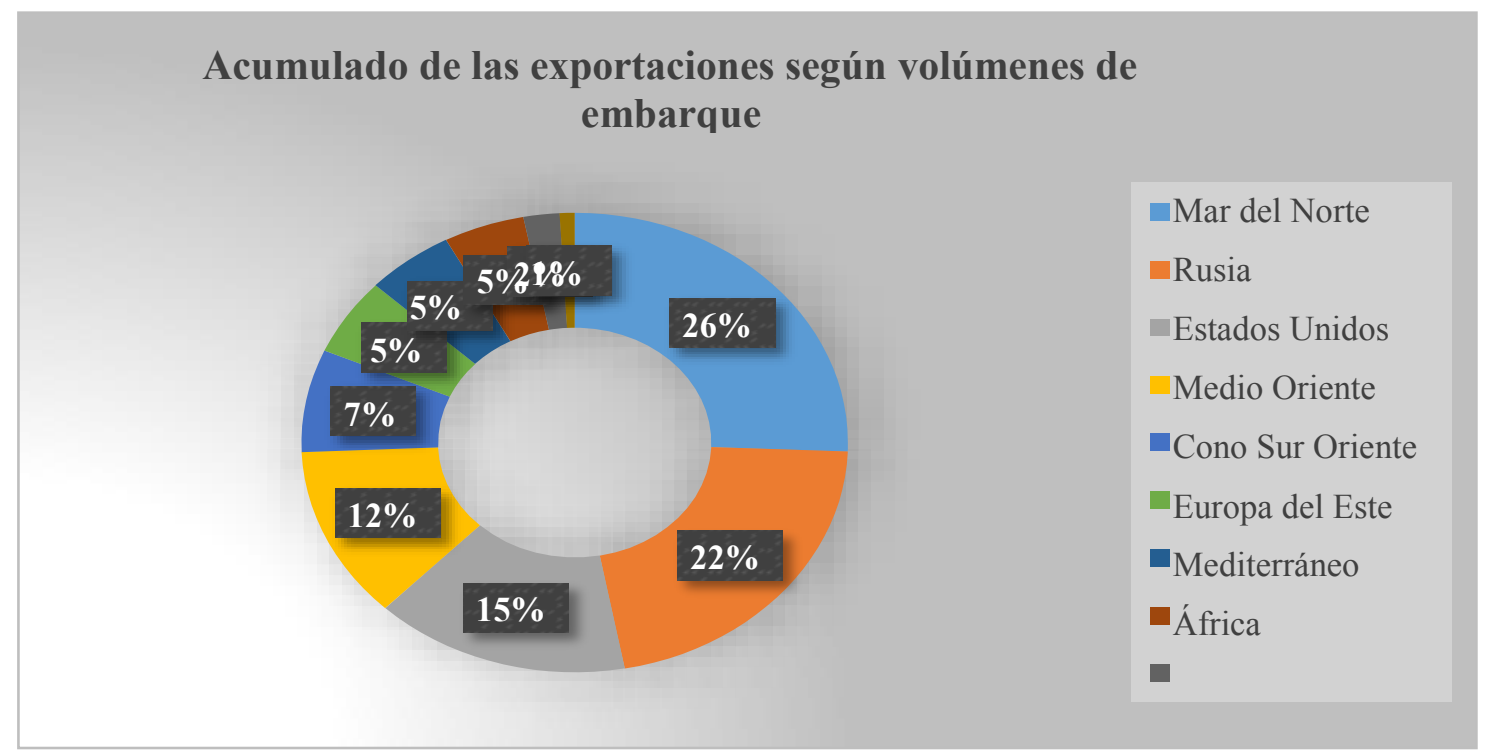

\section{Gráfico 6: Acumulado de exportaciones según volúmenes de embarque}

Fuente: TradeMap

En la figura anterior se detalla que los países del Mar del Norte, Rusia, Estados Unidos y Medio Oriente son los principales destinos del banano ecuatoriano siendo que ellos suman el $74,35 \%$ de las exportaciones.

Al contar Ecuador con costas escarpadas favorables para la exportación además de tener lugares propicios para la construcción de puertos de aguas profundas que posibilitarían el arribo de buques de mayor calado a nuestras costas el país actualmente cuenta con puertos como el de Guayaquil del que se exportaron en el 2015 según datos de la A.E.B.E. 234, 291,500 cajas, lo que representa el $73.81 \%$ y, por el Puerto Bolívar con 83, 145,540 cajas, equivalente al $26.19 \%$.

Según información de los productores en zonas de la provincia de El Oro, argumentan que la producción se encuentra en condiciones normales con relación al año anterior, añadieron que el clima no les fue favorable porque la sequía se mantuvo más tiempo de lo esperado, sumiendo a las plantaciones bajo una fuerte etapa de vientos que degradaron la calidad de los cultivos.

Es por ello que los resultados obtenidos no fueron los esperados por los productores puesto que se han mantenido en los niveles productivos del año pasado. Cabe recalcar que estas plantaciones se combina el cultivo de banano tradicional que utiliza insumos químicos y el orgánico que no necesita estos aditamentos, sin embargo, el precio de la mano de obra requerida para las plantaciones ahondó más la situación ya que implicó un aumento de la inversión en la cosecha.

Las ingentes inversiones realizadas por los dueños de las plantaciones fueron para 
frenar en parte los estragos provocados por el Fenómeno de El Niño, entre otras las de construir obras de infraestructura en sus instalaciones, mantenimiento de las fincas para disminuir el impacto de las lluvias, a esto le añadimos los créditos otorgados por BanEcuador para desarrollo y construcción de infraestructuras, limpieza y ampliación de canales de drenaje, construcción de pozos, etc.

Si bien se estableció a finales del 2015 el precio de la caja de 43 libras en USD 6.55 para los productores de banano, estos precios no se cumplieron en la realidad debido a que los productores con un promedio de hectáreas destinadas para la siembra oscilante entre las 8 y las 10 hectáreas recibieron apenas USD 3.80 por la caja, valores insuficientes si se tiene en consideración que el costo de producción es de USD 4.70.

Por otro lado, los pequeños productores que poseen hasta 4 hectáreas de plantaciones de banano solo alcanzan a subsistir debido a que no es rentable al precio que el exportador les paga, ya que este cultivo es a gran escala. Este cultivo también cuenta con seguro agrícola, el mismo que sólo cubre el primer año de siembra.

Entre los inconvenientes que tienen los pequeños productores se aprecia que las grandes exportadoras al facturar la compra lo registran al precio oficial, pero al agricultor solamente se le estaba cancelando un valor proporcional por lo que los agricultores se sienten desprotegidos y carecen del apoyo de las entidades gubernamentales correspondientes.

En el presente año de acuerdo a lo manifestado por oficiales de crédito de BanEcuador como por los productores de banano estiman un crecimiento sostenido del $4 \%$ al finalizar el 2016, dependiendo de las condiciones climatológicas que se prevé con el arribo del Fenómeno de El Niño y la temporada invernal que no afecten de forma considerable a las plantaciones por causa de este fenómeno natural.

Aparte a los problemas acaecidos por parte de la naturaleza los precios bajos por la venta de la caja de banano, los elevados costos de los insumos que afectan sobre todo al pequeño productor.

En el 2016 el volumen de cosecha de banano fue de un promedio de 2210 cajas de 18,45 kilos por hectárea. En tanto se destacan que los créditos concedidos por el BanEcuador durante el periodo 2016, montos y números de créditos entregados a los productores para la siembra y cultivo de banano se incrementaron.

Tabla 8. Créditos concedidos al sector agropecuario por BanEcuador

\begin{tabular}{|c|c|c|c|c|c|c|c|c|}
\hline & \multicolumn{8}{|c|}{ Años. } \\
\hline & 2016 & 2015 & & & 2016 & 2015 & & \\
\hline Subsector Rubro & $N^{\circ} 0$ peraciones & No Operaciones & Albsoluta & Relativa & Valor en dólares & Valor en dólares & Albsoluta & Relativa \\
\hline Toral cosdito original. & 35 & 31 & 4 & 1290 & 578362 & 428277 & 150085 & 35.04 \\
\hline A aricola Banano & 35 & 31 & 4 & 1200 & 578362 & 428277 & 150085 & 35.04 \\
\hline
\end{tabular}

Fuente: BanEcuador

La tabla anterior muestra que el número de los créditos aprobados por BanEcuador en el 2016 se incrementaron en un 12,90\% comparado al año 2015. 
De forma similar si hacemos una relación de los valores entregados en el mismo periodo de estudio el BanEcuador desembolsó USD 578,362 para producción de banano, lo que significa un crecimiento de $35.04 \%$, con relación a los USD 428,277 que costeó en el 2014, lo que significa una variación absoluta positiva de USD 150,085 .

Según el Acuerdo Ministerial No. 350 de diciembre 8 de 2015, se estableció el precio de la caja de banano que empezó a regir desde el 1 de enero al 31 de diciembre del 2016, partiendo de referencia la caja a un valor de USD 6.16. Volumen de producción de Banano

De la medición de los años partiendo desde el 2012 hasta el 2015. En el 2012 hubo un decrecimiento del 2\% comparado con el año 2011, en el 2013 el volumen de producción de banano creció en un $10 \%$, desde la apreciación del dólar la producción de banano empezó a reducirse creciendo en el 2014 solamente el 3\% y en el 2015 reducir en un $1 \%$.

VOLUMEN DE PRODUCCIÓN DE BANANO

(Variación semestral porcentajes, 2012-2015)

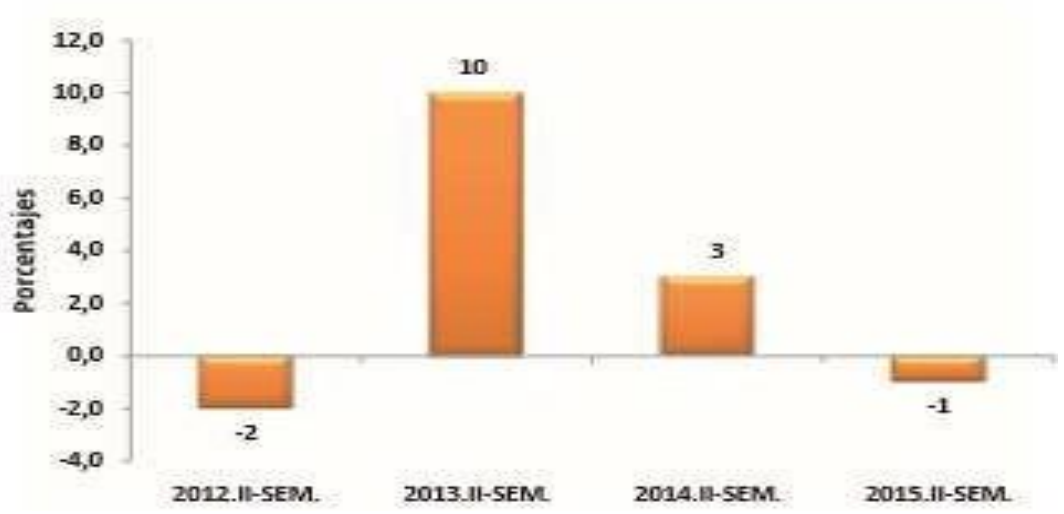

Gráfico 7: Volumen de producción de banano Fuente: Banco Central del Ecuador (B.C.E.) 


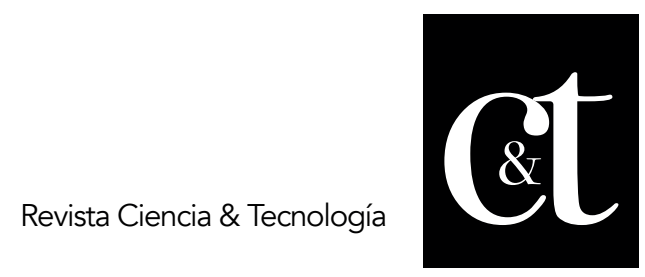

No. 22, 30 de abril de 2019

ISSN impreso: 1390 - 6321

ISSN online: 2661 - 6734

Precio de banano

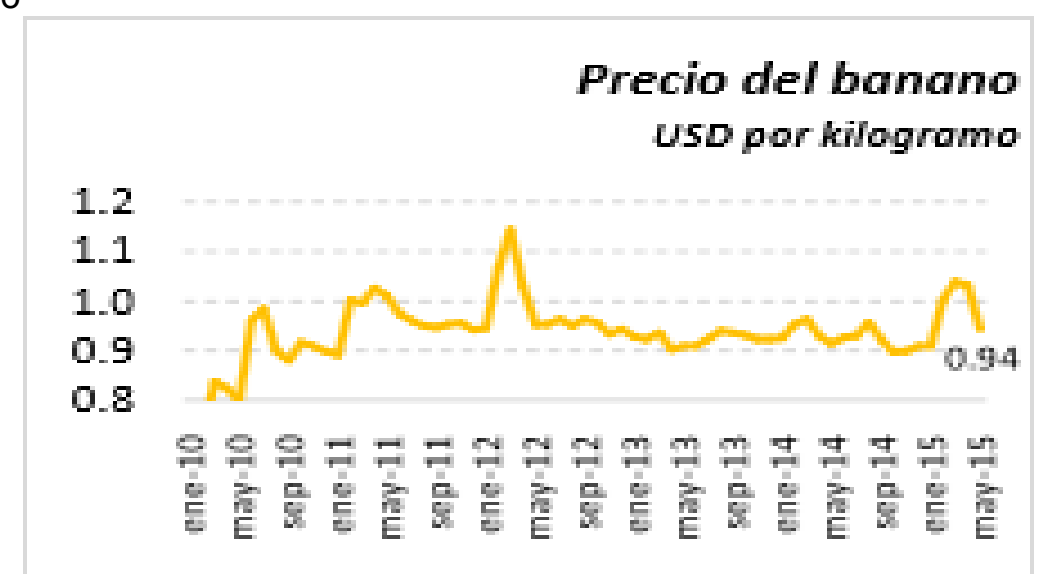

Gráfico 8. Precio de banano por kilogramo

Fuente: Banco Mundial

El precio estándar del kilogramo del banano a través del tiempo ha ido evolucionando entre crecimientos y decrecimientos, en los últimos años el precio se ha mantenido en el promedio de los 0,90 centavos el kilogramo, hasta el primer trimestre del 2015 el precio se colocó sobre la barrera de un dólar por kilo hasta irse reduciéndose de a poco.

Tabla 9. Exportaciones en valor FOB

\begin{tabular}{|c|c|c|c|c|c|c|c|}
\hline \multirow[b]{2}{*}{ Destinos } & \multirow[b]{2}{*}{ Unidades } & \multicolumn{3}{|c|}{ Ene-Abr } & \multicolumn{2}{|c|}{ Variaciones } & \multirow{2}{*}{ Part. 2016} \\
\hline & & 2014 & 2015 & 2016 & $2014-2015$ & 2015-2016 & \\
\hline \multirow{2}{*}{ Rusia } & Fob Miles USD & 176.701 & $\begin{array}{|ll|}\text { S } & 215.839 \\
\end{array}$ & 202.299 & 22,15 & $-6,27$ & 24,44648569 \\
\hline & Toneladas & 434.495 & 517.527 & 481.544 & 19,11 & $-6,95$ & 25,18488635 \\
\hline \multirow{2}{*}{$\begin{array}{l}\text { Es tados } \\
\text { Unidos }\end{array}$} & Fob Miles USD & 145.535 & 150.845 & 149.476 & 3,65 & $-0,91$ & 17,08509645 \\
\hline & Toneladas & 342.994 & \begin{tabular}{|l|}
328.553 \\
\end{tabular} & 330.814 & $-4,21$ & 0,69 & 15,98867299 \\
\hline \multirow{2}{*}{ Turquia } & Fob Miles USD & 21.539 & 74.535 & 54.460 & 246,05 & $-26,93$ & 8,442027672 \\
\hline & Toneladas & 55.534 & 176.491 & 128.333 & 217,81 & $-27,29$ & 8,5887418 \\
\hline \multirow{2}{*}{ Alemania } & FobMiles USD & 82.196 & 57.966 & 105.360 & $-29,48$ & 81,76 & 6,565379702 \\
\hline & Toneladas & 204.404 & 133280 & 242.659 & $-34,80$ & 82,07 & 6,485925668 \\
\hline \multirow{2}{*}{ Italia } & Fob Miles USD & 86.922 & 56.633 & 42.138 & $-34,85$ & $-25,59$ & 6,41440066 \\
\hline & Toneladas & 215.892 & 120.820 & 97.648 & $-44,04$ & $-19,18$ & 5,879573373 \\
\hline \multirow{2}{*}{ Otros paises } & Fob Miles USD & 260.700 & 327.086 & 345.027 & 25,46 & 5,49 & 37,04660982 \\
\hline & Toneladas & 679.459 & 778.240 & 810.745 & 14,54 & 4,18 & 37,87219982 \\
\hline \multirow{2}{*}{ TOTAL } & Fob Miles USD & 773.593 & 882.904 & 898.760 & 14,13 & 1,80 & 100 \\
\hline & Toneladas & 1.932 .778 & 2.054 .911 & 2.091 .743 & 6,32 & 1,79 & 100 \\
\hline
\end{tabular}

Fuente: TradeMap

La exportación hacia los diferentes mercados del banano ecuatoriano ha ido variando a través del tiempo siendo el mercado más importante la Federación rusa que en el periodo 2016 tuvo una variación negativa de 6,27\% comparado con el 2015, esto 


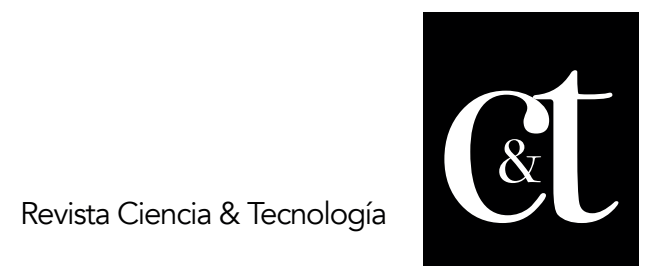

No. 22, 30 de abril de 2019

ISSN impreso: 1390 - 6321

ISSN online: 2661 - 6734

debido a la apreciación del dólar en comparación a su par ruso el rublo (Expreso, 2015).

Evolución de exportaciones de Banano

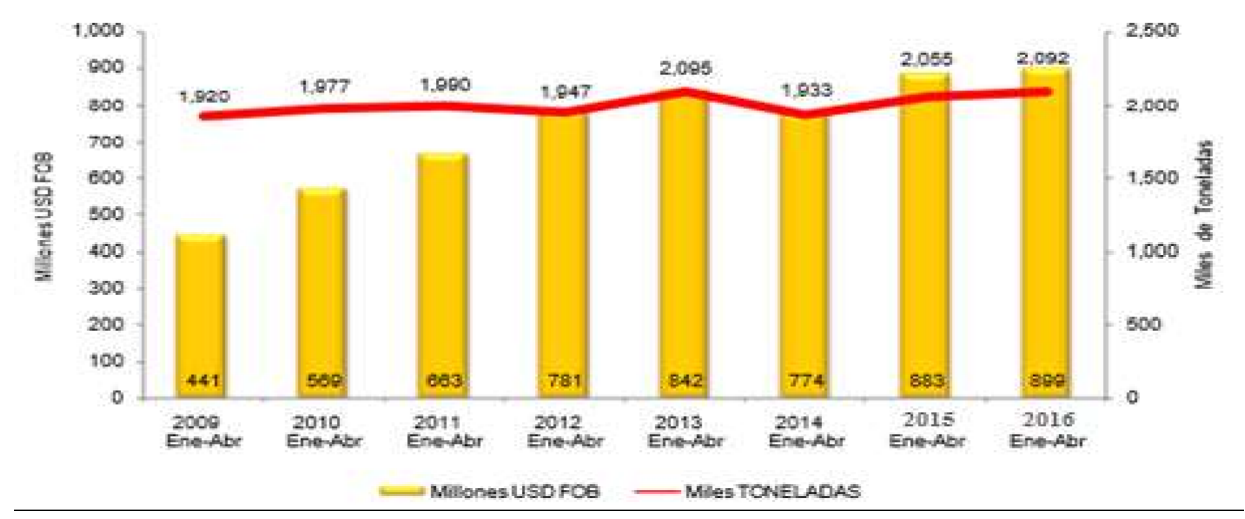

Gráfico 9. Crecimiento de exportaciones

Fuente: Banco Central del Ecuador (B.C.E.)

El Ecuador desde 1950 ha ido creciendo incipientemente en la exportación de banano al mundo, el Banco Central del Ecuador (BCE) ente rector de la economía ecuatoriana ha realizado las estimaciones de exportaciones en millones de USD y miles de toneladas por lo que en el periodo de enero a abril desde el 2009 hasta el 2016 la cantidad de dinero resultante de la exportación ha ido creciendo favorablemente para la economía ecuatoriana, salvo un declive en el 2014 que mermó una cantidad considerable de ingresos a las arcas públicas para luego en los años subsiguientes acrecentar la cantidad exportable y por ende aumentar la cantidad de divisas que ingresan al país por respecto de las exportaciones de la fruta (Comercio, 2015).

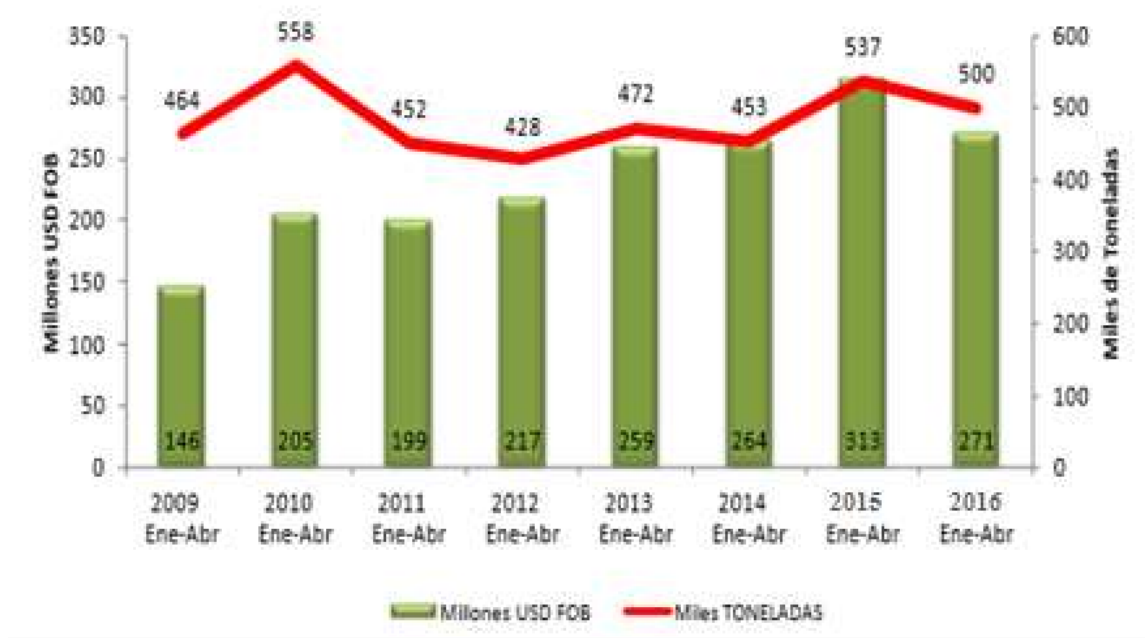

Gráfico 10. Evolución de exportaciones a Rusia

Fuente: Banco Central del Ecuador (B.C.E.) 


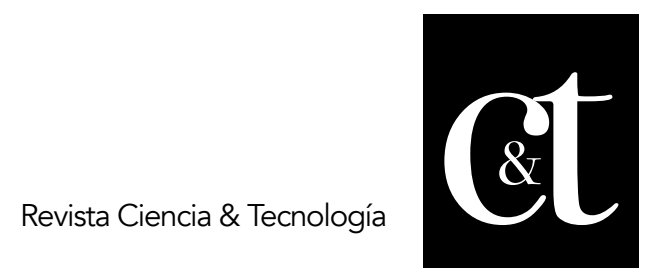

El mercado ruso a través del tiempo ha ido abriendo sus puertas paulatinamente a los productos ecuatorianos, especialmente al banano siendo Rusia el principal mercado del Ecuador, desde el 2009 hasta el 2015 el BCE registró un crecimiento de las exportaciones hacia ese país en millones de USD FOB, en el 2016 se produce un decrecimiento de la cantidad exportable al gigante euroasiático que genera en la disminución de 37 mil toneladas hacia ese destino.

Según Irina Koziy, Directora General de FruitNews, asevera que el banano ecuatoriano cuenta con una sostenida y creciente demanda en el país, estimaciones que pueden mejorar con políticas de promoción e incentivo por la fruta que promuevan una alimentación saludable y sostenible para proveer de un mayor crecimiento de los valores ya importados por el país. Hace 9 años el consumo anual promedio de una persona era de 36 kilogramos, el año pasado aumentó a 71 kilogramos. Se ha duplicado debido a que ahora es considerado barato y eso impulsa su consumo.

De acuerdo a las aseveraciones de FruitNews el banano ecuatoriano es uno de los productos más consumidos en la Federación Rusa, es por ello que la fruta ecuatoriana en el 2016 representó más del $90 \%$ de las importaciones totales.

Actualmente el banano se comercializa a través de diferentes proveedores entre ellos el $50 \%$ se comercializa a través de supermercados mientras que hace unos años atrás apenas alcanzaba un $12 \%$.

Los rusos prefieren el banano ecuatoriano debido a que se transporta muy bien, su presentación es vital al igual que su preservación, se precisa mantenerlo guardado y no disminuye su presentación, sin duda es una gran ventaja en comparación a los otros países exportadores.

\section{Consecuencias para el sector bananero en las exportaciones hacia el mercado ruso}

La apreciación del dólar

El Banco de La Reserva Federal de los Estados Unidos estudia con preocupación la apreciación del dólar debido a sus efectos contrarios en el sector externo de dicho país. Esta apreciación puede aumentar debido al carente crecimiento e inflación de la zona euro lo que podría provocar un crecimiento menor de la potencia americana. Las medidas tomadas por el Banco Central Europeo para promover el euro han ocasionado que la divisa esté en los mínimos en su relación con el dólar, además de una posible reducción en las expectativas de crecimiento en los países asiáticos como China o Japón, sin contar con las perspectivas de conflicto en Medio Oriente.

A raíz de esto, la Reserva Federal instó su intención de sostener las tasas de interés oscilantes entre el $0 \%$ y el $0,25 \%$ por un tiempo prolongado con el propósito de fortalecer la economía y reducir el estimado de adquisición de bonos. La apreciación del dólar aumenta el valor de las ventas de productos al exterior y disminuye el precio de las importaciones, esta situación es compartida por las economías dolarizadas como la del Ecuador, Panamá y El Salvador, exportaciones que pierden competitividad con el resto de los países de la región que aplican políticas monetarias que hacen más competitivas a los países mediante la devaluación de sus monedas, lo que les vuelve más atractivas para los mercados de crecimiento en el mundo, 


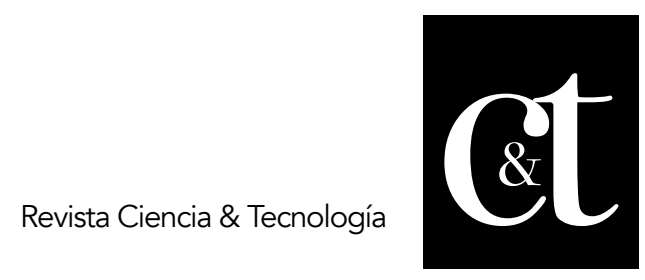

No. 22, 30 de abril de 2019

ISSN impreso: 1390 - 6321

ISSN online: 2661 - 6734

además de los ya consolidados como la Federación Rusa.

Por otro lado, la apreciación del dólar ocasionará un incremento del valor de las remesas enviadas los migrantes o familiares desde los Estados Unidos hacia el resto del mundo, en especial a los países latinoamericanos.

\section{Tabla 10. Cantidad exportable a Rusia}

\begin{tabular}{|l|l|l|c|c|c|}
\hline \multirow{2}{*}{$\begin{array}{l}\text { Código del } \\
\text { producto }\end{array}$} & \multirow{2}{*}{ Descripción del produc to } & \multicolumn{4}{|c|}{ Rusia, Federación de importa des de Ecuador } \\
\cline { 3 - 6 } & & $\begin{array}{c}\text { Valor en } \\
\mathbf{2 0 1 3}\end{array}$ & $\begin{array}{c}\text { Valor en } \\
\mathbf{2 0 1 4}\end{array}$ & $\begin{array}{c}\text { Valor en } \\
\mathbf{2 0 1 5}\end{array}$ & $\begin{array}{c}\text { Valor en } \\
\mathbf{2 0 1 6}\end{array}$ \\
\hline 0803901000 & Plátanos frescos o secos (plátanos exc1.) & 821647 & 949814 & 898219 & 881010 \\
\hline
\end{tabular}

Fuente: TradeMap

Las exportaciones a Rusia a partir del 2013 empezaron a disminuir a causa de variados factores entre ellos por la apreciación del dólar en el mercado mundial esto a causa del no crecimiento por parte del mercado de la Unión Europea (UE) por lo que se prevé una reducción de la cuota exportable al gigante euroasiático.

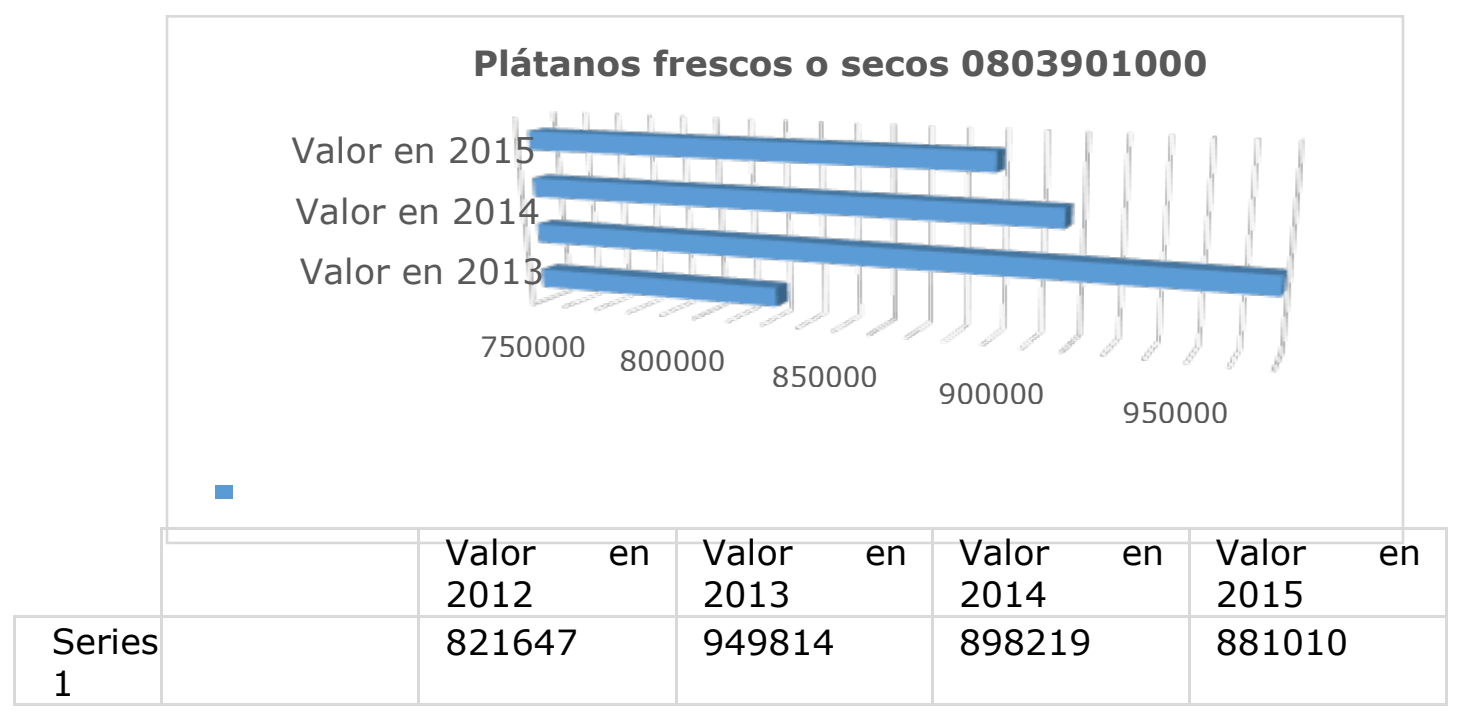

\section{Gráfico 11. Evolución de exportaciones de plátanos frescos}

Fuente: TradeMap

El impacto de las importaciones de Rusia al Ecuador en el mercado mundial puede evidenciarse en la tabla que se presenta a continuación. En el mismo se ve la tasa de participación en el período 2011-2015. Corresponde a plátanos (bananos) secos y frescos, junto con el arancel equivalente ad valorem impuesto por la Federación Rusa al Ecuador.

Estas estadísticas muestran la importancia de este commodity para la generación de ingresos para el Ecuador, así como la vulnerabilidad de los precios frente 


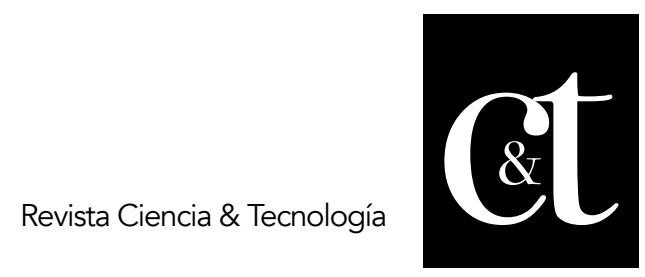

No. 22, 30 de abril de 2019

ISSN impreso: 1390 - 6321

ISSN online: 2661 - 6734

apreciaciones o depreciaciones de la moneda.

Tal como lo muestra la teoría económica, la susceptibilidad de las monedas frente a la fortaleza o debilidad de las mismas, genera desequilibrios serios en la balanza comercial de los países, generando incluso problemas a nivel de la balanza de pagos.

Esto tiene que ver con la vulnerabilidad de la moneda frente a otras en los mercados internacionales de divisas. Los problemas en la balanza comercial son muy difíciles de enfrentar cuando no se cuenta con una moneda propia, tornándose la dependencia en los Estados Unidos. Los ajustes cambiarios son nulos en el Ecuador, dado que se ha adoptado una moneda extranjera.

Tabla 11. Banano importado desde Ecuador a Rusia

\begin{tabular}{|c|c|c|c|c|}
\hline \multirow[b]{2}{*}{$\begin{array}{l}\text { Descripción } \\
\text { del producto }\end{array}$} & \multicolumn{4}{|c|}{ Federación de Rusia importa desde Ecuador } \\
\hline & $\begin{array}{l}\text { Valor } \\
2016 \text {, en } \\
\text { miles } \\
\text { US\$ }\end{array}$ & $\begin{array}{l}\text { Tasa de } \\
\text { crecimiento } \\
\text { anual en } \\
\text { valor entre } \\
2011-2015 \text {, } \\
\% \text {, p.a. }\end{array}$ & $\begin{array}{l}\text { Participación en } \\
\text { las } \\
\text { importaciones } \\
\text { de Rusia, } \\
\text { Federación de } \\
, \%\end{array}$ & $\begin{array}{l}\text { Arancel } \\
\text { equivalente } \\
\text { ad yalorem } \\
\text { aplicado por } \\
\text { Rusia, } \\
\text { Federación } \\
\text { de a } \\
\text { Ecuador }\end{array}$ \\
\hline \multirow{3}{*}{$\begin{array}{l}\text { Plátanos, } \\
\text { incl. } \\
\text { plátanos, } \\
\text { frescos } \\
\text { secos }\end{array}$} & 896225 & 2 & 98,5 & 3,2 \\
\hline & \multicolumn{3}{|c|}{ Ecuador exporta hacia el mundo } & \\
\hline & $\begin{array}{l}\text { Valor } \\
2016 \text {, en } \\
\text { miles } \\
\text { US\$ }\end{array}$ & $\begin{array}{l}\text { Tasa de } \\
\text { crecimiento } \\
\text { anual en } \\
\text { valor entre }\end{array}$ & $\begin{array}{r}\begin{array}{r}\text { Participación en } \\
\text { las }\end{array} \\
\text { exportaciones } \\
\text { mundiales, \% }\end{array}$ & \\
\hline
\end{tabular}




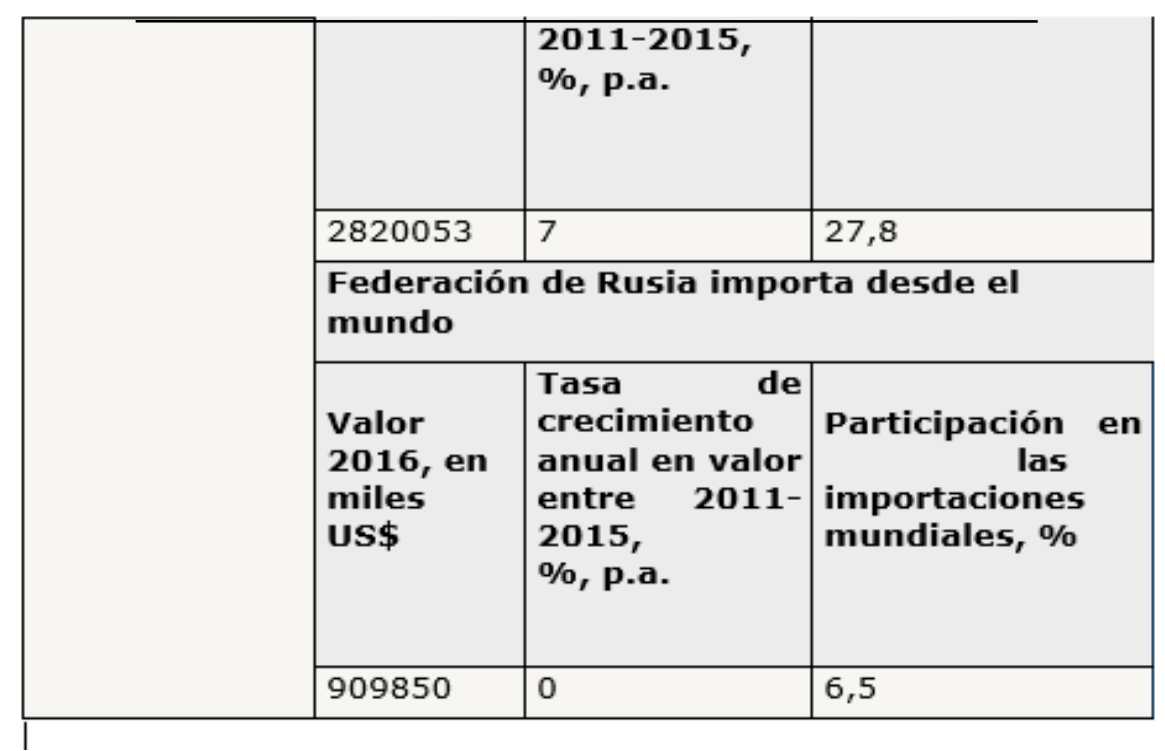

Fuente: TradeMap

A continuación de detalla un comparativo de exportaciones del Ecuador por destino.

El Ecuador es un país rico en biodiversidad y variedad de entornos, la bonanza bananera lo demuestra, es por ello que actualmente el país exporta el equivale al $27,8 \%$ del total de las exportaciones mundiales de banano, siendo además el principal socio comercial con la Federación Rusa abarcando el 98,5\% de dicho mercado y terminar en promedio desde el 2011 al 2015 con un crecimiento no sostenido del $2 \%$. Cabe hacer notar que el país al igual que el resto de exportadores está sujeto al arancel del 3,2\% que responde a las importaciones de banano, este arancel solo está libre para Bielorrusia.

En la tabla a continuación se presentará el detalle de las exportaciones por destino económico en los años 2015 y 2016, donde se puede apreciar las variaciones existentes, así como el peso en cada destino.

Resulta un porcentaje no muy significativo en el resultado final. Sí sorprende la región africana con su respectivo crecimiento. En Europa Oriental se ha perdido mercado, según lo demuestran las estadísticas. 
Tabla 12. Comparativo de exportaciones

\begin{tabular}{|c|c|c|c|c|}
\hline Destino & 2015 & 2016 & Valor absoluto & $\%$ \\
\hline África & 3.191 .207 & 6.767 .913 & 3.576 .706 & 112,08 \\
\hline Medio Oriente & 29.458 .156 & 38.611 .346 & 9.153 .190 & 31,07 \\
\hline Oriente & 13.442 .386 & 17.250 .629 & 3.808 .243 & 28,33 \\
\hline Oceania & 2.318 .102 & 2.809 .334 & 491.232 & 21,19 \\
\hline Estados Unidos & 44.710 .461 & 47.982 .908 & 3.272 .447 & 7,32 \\
\hline Mar del Norte/ Báltico & 76.391 .274 & 81.308 .397 & 4.917 .123 & 6,44 \\
\hline Cono Sur & 21.860 .549 & 22.910 .511 & 1.049 .962 & 4,80 \\
\hline Rusia & 66.553 .529 & 68.115 .550 & 1.562 .021 & 2,35 \\
\hline Mediterráneo & 16.884 .534 & 15.181.971 & 1.702 .563 & $-10,08$ \\
\hline Europa del Este & 23.250 .549 & 16.498 .481 & 6.752 .068 & $-29,04$ \\
\hline Total & 298.062 .761 & 317.439 .055 & 19.376.293 & 6,50 \\
\hline
\end{tabular}

Fuente: Trade Map

Las exportaciones ecuatorianas tienen destinos muy variados entre ellos los que más se destacan: las del Mar del Norte, seguidas por Rusia y su par norteamericano que juntas representan el $62 \%$ de las exportaciones del Ecuador hacia el mundo, siendo estos los mayores mercados y por contar con el mayor crecimiento dentro del ámbito económico.

El dólar se está comportando al contrario de lo que requiere el país, ya que en vez de depreciarse se aprecia, todo lo contrario sucede con Colombia donde el peso llegó a devaluarse al $85 \%$ y en Perú al $20 \%$, mientras que en promedio el dólar se ha revaluado en $30 \%$ en el Ecuador.

El presidente del Ecuador Rafael Correa señaló que el país ha perdido unos 9.000 millones de dólares en exportaciones debido a la "tormenta perfecta", como ha denominado a las situaciones externas que han afectado a la economía ecuatoriana entre ellas el desplome de las exportaciones, la caída del precio del petróleo, o la apreciación del dólar (Suramérica, 2017)

\section{Conclusiones}

Al contar Ecuador con barreras arancelarias del mismo porcentaje que el resto de países, coyunturalmente se encuentra en desventaja en este momento, debido entre otros aspectos por la apreciación del dólar frente al resto de monedas del mundo, entre ellas el rublo ruso. El país es el mayor socio comercial de banano de Rusia contando con una participación superior al 95\% del mercado, es indudable que la apreciación del dólar resta competitividad al banano ecuatoriano por lo que los importadores rusos optarían por adquirir banano más barato de nuestra competencia, aunque la distinción del banano ecuatoriano se centra en la calidad y textura de la fruta.

La cantidad de banano exportada tiende a incrementar, pero el precio se ve reducido por parte de los compradores, al igual que la disminución de las importaciones por pate de la Federación de Rusia, esto debido a la recesión en la cual se encuentra este 


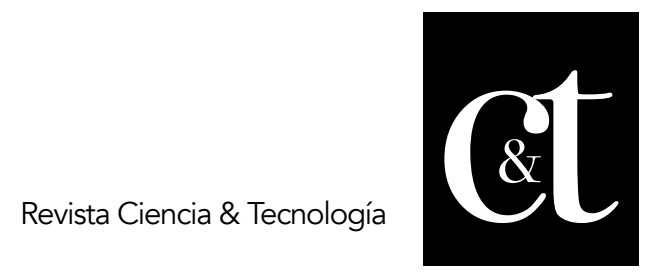

No. 22, 30 de abril de 2019

ISSN impreso: 1390 - 6321

ISSN online: 2661 - 6734

país, que según previsiones empezará a mejorar su economía a mediados del 2017, siempre y cuando no se den shocks externos.

Al ser el dólar la divisa de cambio mundial por excelencia, la más ligera variación en apreciación o en devaluación frente a otras monedas afectaría y afecta notablemente a la economía mundial, estas variaciones actualmente se están dando por medio de las apreciaciones del dólar en la que la moneda se ha apreciado en promedio $30 \%$ en relación a las monedas latinoamericanas. Las causas de la apreciación del dólar van conectadas con situaciones geopolíticas como el incremento de la producción de petróleo y su consecuente desplome de precios, la reducción del crecimiento de la economía China y la zona euro y sus políticas de austeridad en el caso de Grecia, España e Italia, entre otros (El Tiempo, 2015).

En la actualidad debido a la reducción del precio del petróleo, las exportaciones no petroleras son superiores a las exportaciones petroleras razón por la cual la dependencia a las exportaciones como actividad generadora de divisas para la economía ecuatoriana se vuelve imprescindible, motivo por el cual las economías vecinas han visto devaluar sus monedas durante la apreciación del dólar, siendo que el peso colombiano se ha devaluado en un $70 \%$ en comparación al dólar, lo que resta competitividad a las exportaciones ecuatorianas debido al tipo de cambio.

\section{Recomendaciones}

El sector bananero genera empleo a miles de personas del Ecuador, sobre todo a los habitantes de la región costa del país. El punto radica en aumentar la productividad debido a que nuestros competidores tienen economía de escala en la producción de banano, este es el caso de Costa Rica, mientras que el Ecuador tiene una producción realizada por pequeños productores en su gran mayoría y otros grandes poseedores de tierra como lo es el Grupo Noboa, por lo que se debería mejorar el nivel de productividad por hectárea sembrada.

Al encontrarse la Federación de Rusia en una recesión sostenida hasta mediados del 2018 según datos del Banco Mundial, se estima conveniente la pronta firma del acuerdo con la Unión Europea (UE), lo que le proveería al Ecuador el acceso a comercial con un bloque económico rentable que generaría un incremento del ingreso de divisas debido al valor superior del euro frente al dólar lo que generaría un creciente aumento de efectivo para la cuenta corriente del Banco Central.

El banano a diferencia del petróleo es un recurso renovable, por lo que el gobierno debe apoyar al sector bananero abriendo líneas de crédito para una mayor tecnificación y liberando el ingreso de agroquímicos que localmente su precio es muy alto.

Al ser el Ecuador el principal exportador de banano en el mundo, el país debe potenciar el sector bananero a través de la promoción y el sostenimiento de la calidad de la fruta, a través de operaciones conjuntas entre los Ministerios para conseguir los más altos estándares de calidad en cuanto a producción, calificación que nos abrirá mayores mercados y nos mostrará como un país proveedor de materias primas de calidad.

La necesidad de buscar otros mercados para la fruta ecuatoriana requerirá de 


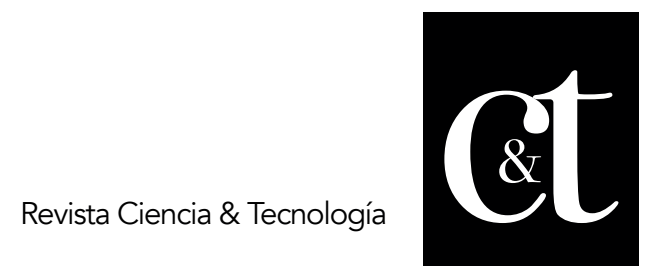

No. 22, 30 de abril de 2019

ISSN impreso: 1390 - 6321

ISSN online: 2661 - 6734

estrategias comerciales eficientes, para evitar la dependencia en un solo mercado clave.

Resulta importante el que se diversifiquen los mercados destino, para efectos de tener un crecimiento más importante y significativo, de manera que también se aumente el potencial para la generación de divisas que tanto requiere el país.

El país, al no contar con moneda propia, es objeto de choques externos en cuanto a la cotización del dólar y a sus respectivas fluctuaciones. Esto vuelve muy vulnerable a la economía ecuatoriana. Por otra parte, debe priorizarse la producción y exportación de este commodity,

\section{Referencias bibliográficas}

Álvarez R., A. (2010). Economía. Perú: Empresa editora El Comercio

Banco Mundial. (2016). Banco Mundial. Obtenido de http://www.bancomundial.org/es/news/press-release/2016/06/07/world-bankcuts-2016-global-growth-forecast

Carty. (2017). eHow. Obtenido de http://www.ehowenespanol.com/factores- afectarapreciacion-depreciacion-moneda-lista_139517/

Castillo, J. (2007). Economía general. Chiclayo: Editora USAT. Hill, Ch.

Centro de Comercio Internacional. (2017). TRADE MAP. Obtenido de http://www.trademap.org/Bilateral_10D_TS.aspx?nvpm $=3$

Centro de Estudios Estratégicos-CEE (2015). Centro de Estudios Estratégicos. http://cespe.espe.edu.ec/el-regreso-del-rey-dolar-a-latinoamerica/

Dabrowsky, M. (31 de octubre2015). El Mundo. Obtenido de http://www.elmundo.es/economia/2015/10/31/5633687522601d716e8b4620.h tml

Diario Expreso. (1 de Junio de 2015). Diario Expreso. Obtenido de http://expreso.ec/economia/la-economia-rusa-se-contrae-2-4-y-afecta-laCQGR_8017255

Filomenko, D. (7 de 04 de 2015). Russia Beyond the Headlines. Obtenido de http://es.rbth.com/economia/2015/04/07/espectacular_recuperacion_del_rublo _f rente_al_dolar_y_el_euro_48789

Filomenko, D. (s.f.). DW. (11 de Abril de 2016). DW. Obtenido de http://www.dw.com/es/continuar\%C3\%A1-desaceleraci\%C3\%B3necon\%C3\%B3mica-de-china-dice-el-banco-mundial/a-19177578

Eco-Finanzas. (2015). Eco-Finanzas. Obtenido de Diccionario Economía Administración-Finanzas-Marketing: Descargado de: http://www.ecofinanzas.com/diccionario/B/BIENES_DE_CONSUMO.htm

El Telégrafo. (1 de Octubre de 2015). El Telégrafo. Obtenido de http://www.eltelegrafo.com.ec/noticias/economia/1/fmi-la-caida-de-precios-delas-materias-primas-afectaria-la-economia-global 
El Tiempo. (6 de Junio de 2015). El Tiempo. Obtenido de http://www.eltiempo.com/mundo/europa/crisis-en-grecia-el-dificil-dilema-de-launion-europea-sacar-a-grecia-del-euro-o-ceder/16049797

Férrero, Á. (17 de Enero de 2016). Público.es. Obtenido de http://www.publico.es/internacional/rusia-crisis-economica-y-inestabilidad.html

Forbes México. (5 de Diciembre de 2014). Forbes México. Obtenido de http://www.forbes.com.mx/caida-en-precios-de-materias-primas-afectaralatinoamerica/\#gs.Az2KxsY

Fuenmayor B. (18 de Marzo de 2015). Pontificia Universidad Católica del Ecuador. Obtenido de Ventaja comparativa: el Banano en el Ecuador.: http://www.puce.edu.ec/economia/efi/index.php/economia-internacional/12teoria-clasica/219-ventaja-comparativa-el-banano-en-el-ecuador

Grupo El Comercio. (5 de Enero de 2016). El Comercio. Obtenido de http://edicionimpresa.elcomercio.com/es/07230001e91b9092-a1f1-4acf-b563a4dbefb07b25

Herrera V., B. \& Caballero B., J. (2012). "Dolarizar: ¿realmente un dilema?". Bogotá: Cuadernos de Economía No. 36.

Herrera, W. (12 de Octubre de 2015). Diario El Comercio. Obtenido de http://www.elcomercio.com/opinion/washington-herrera-opinion-dolareseconomia.html.

Krugman, Paul y Obstfeld, Maurice. (2011). Economía Internacional, Cuarta Edición.

España: McGraw Hill.

López Domínguez, I. (2020). Expansión. Obtenido de http://www.expansion.com/diccionario-economico/depreciacion.html

Macas, G. (2014). Revista el Agro. Obtenido de "Cinco países concentran el 69.5\% de la exportación del banano":

http://www.revistaelagro.com/2014/03/28/cinco- paises-concentran-el-695-dela-exportacion-de-banano/

PRO ECUADOR. (2013). Análisis del sector bananero. Instituto de promoción de exportaciones e inversiones. http://www.proecuador.gob.ec/wpcontent/uploads/2013/09/PROEC_AS2013_BANANO.pdf.

Pro Ecuador. (15 de Octubre de 2016). Pro Ecuador. Obtenido de Instituto de promoción de exportaciones e inversiones:

http://www.proecuador.gob.ec/compradores/oferta-exportable/banano/

Revista Líderes. (13 de 10 de 2015). Revista Lideres. Obtenido de http://www.revistalideres.ec/lideres/apreciacion-dolar-preocupa.html

Rodriguez, A. (2007). Spentamexico. Obtenido de http://www.spentamexico.org/v2- n2/2(2)\%20156-228.pdf

Suramérica, A. P. (7 de Agosto de 2017). 92 btenido de: 


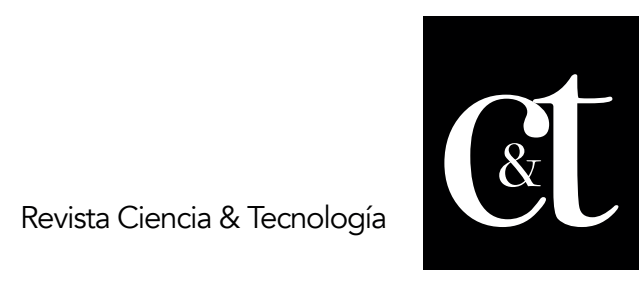

No. 22, 30 de abril de 2019

ISSN impreso: 1390 - 6321

ISSN online: 2661 - 6734

http://www.andes.info.ec/es/noticias/ecuador-perdido-9000-millones-dolaresexportaciones-conjuncion-factores-tormenta-perfecta

Kaswani, K. (13 de Noviembre de 2015). BBC. Obtenido:

http://www.bbc.com/mundo/noticias/2015/11/151113_economia_por_que_imp

o rta_caida_precios_materias_primas_ch 